\title{
Cambios en las relaciones familiares y en la solidaridad familiar*
}

\author{
Gerardo A. Meil
}

Arbor CLXXVIII, 702 (Junio 2004), 263-312 pp.

Como se ha argumentado en «La familia española en el contexto de la Unión Europea», publicado en este mismo número, la vida familiar en España, hoy como en el pasado y como en los demás países, está sujeta a un profundo proceso de cambio caracterizado por una privatización creciente de los proyectos de vida familiar, privatización que implica una mayor autonomía individual en relación a la configuración de los proyectos de vida y de formación de una familia. En este trabajo se quiere analizar en qué medida este proceso de cambio está alterando o no las bases de la solidaridad entre los miembros de la familia. En este contexto utilizaremos el significado sociológico de familia, entendiendo por tal toda unión de un hombre y una mujer con vocación de estabilidad en el tiempo, que comparten una vivienda y una economía común así como los asecendientes, descendientes y colaterales comunes, con los que no necesariamente tiene que mantener ni vivienda ni economía común. Esto es, por familia entenderemos un grupo definido por lazos de parentesco consanguíneos o políticos más amplio que la definición estadística de hogar (persona(s) que comparten una vivienda y economía común). Para este análisis nos basaremos mayormente en los datos de una encuesta levantada en la Comunidad de Madrid a finales del 2000, a falta de datos su-

\footnotetext{
* Este trabajo ha sido posible gracias a la financiación recibida de la Comunidad de Madrid, Proyecto 06/0030/99, así como del Ministerio de Ciencia y Tecnología, Proyecto BSO 2001-0161 a quienes el autor agradece el apoyo recibido. Una versión anterior de este trabajo ha sido publicada en Fundación Encuentro (2001), Informe España 2001, Madrid, distribuido por Siglo XXI.
} 
ficientes para todo el territorio nacional. No obstante, y a reserva de las características específicas de cada región, consideramos que si bien los porcentajes no son directamente extrapolables a todas las CC.AA., las características estructurales básicas de la solidaridad familiar y sus pautas de cambio, que son las que aquí se analizan, sí son representativas de todo el conjunto nacional, máxime si se tiene presente que se trata de una Comunidad Autónoma en la que el grado de modernización social está muy avanzado. Esta encuesta se realizó durante el mes de noviembre de 2000 a una muestra representativa de 922 hombres y mujeres cabezas de familia o su cónyuge de 650 menos años ${ }^{1}$ y nos referiremos a ella como «Encuesta madrileña sobre relaciones familiares». Para abordar esta cuestión analizaremos primero las características estructurales que presenta la red familiar y las relaciones entre sus miembros, atendiendo también a la presencia de conflictos, para a continuación abordar las pautas que siguen los flujos de ayuda mutua dentro de lo que podríamos denominar la «economía solidaria familiar» y discutir finalmente en qué medida el proceso de privatización de los proyectos de vida familiar y la pérdida del control social ejercido sobre éstos está erosionando las bases de la solidaridad familiar.

La tesis que se mantendrá, es que a pesar del profundo cambio que está conociendo la realidad familiar española, la solidaridad familiar, y particularmente la solidaridad entre las generaciones, lejos de presentar signos de debilitamiento se ha fortalecido, aunque está sujeta a un proceso de redefinición en el que el apoyo mutuo comienza a fundamentarse sobre unas nuevas bases en las que la percepción subjetiva de independencia dentro de la red familiar juega un papel creciente.

\section{Cambios estructurales en las redes de parentesco}

Al hacerse referencia al tamaño de la familia es muy frecuente centrar la atención en el tamaño de los hogares, pudiéndose constatar que el número de miembros que componen los hogares ha caído de forma sistemática a lo largo de las últimas décadas. Así, el tamaño medio de los hogares ha pasado de alrededor de cuatro miembros a lo largo de la década de los 60 a 2,9 en 2001. Comparativamente con el resto de los países de la Unión Europea, sin embargo, los hogares españoles aparecen como relativamente grandes, pues la media comunitaria se sitúa en 2,6 miembros por hogar, $\mathrm{y}$, de hecho, es uno de los países con mayor tamaño relativo de sus hogares (Eurostat, 2002). Detrás de este proceso de re- 
Cambios en las relaciones familiares y en la solidaridad...

ducción del tamaño de los hogares se encuentran las profundas transformaciones que ha conocido la sociedad española en el pasado reciente, debiéndose destacar como causas más inmediatas, por un lado, los efectos derivados de la caída de la natalidad y de la reducción del tamaño de la descendencia y, por tanto, de las familias y, por otra parte, la tendencia a que los mayores permanezcan durante cada vez más tiempo en su propio hogar (Fundación Encuentro, 2001) y que se traduce tanto en un aumento de los hogares de dos personas como de los hogares unipersonales. Así, la proporción de hogares unipersonales dentro del conjunto de los hogares ha aumentado un 53\% a lo largo de la década de los noventa para situarse en el 20,3\% en el año 2001; en el extremo opuesto, los hogares de 6 o más miembros se han reducido a menos de la mitad, pasando a representar sólo un 4,8\% del total de hogares, y los de 5 miembros también han disminuido en un 34\% para representar sólo un 7,8\% del total de hogares. Los hogares que, por el contrario, han aumentado tanto en número como en peso son los formados por dos y tres personas, siendo particularmente pronunciado el de dos personas (han registrado un aumento del $15 \%$ para pasar a representar uno de cada cuatro hogares) (véase también tabla 15, más adelante) (INE, 2004).

El reducido tamaño de los hogares no refleja, sin embargo, adecuadamente el tamaño real de las redes de parentesco que se extienden más allá de los límites de los hogares. Las estadísticas de hogares no reflejan el tamaño real de las familias e inducen además a error cuando a partir de las mismas se pretende deducir la importancia de la vida familiar en un momento temporal determinado (Bertram, 2000; Nave-Herz, 2002). En términos generales, el tamaño de la red de parentesco está condicionado fundamentalmente por la evolución demográfica que ha conocido y conoce la región de procedencia de los padres. Por tanto, en la actualidad, el tamaño de la red de parentesco está definido básicamente por las características de la transición demográfica que ha conocido España durante el pasado siglo. Así, si bien la transición demográfica ha supuesto un descenso paulatino de la fecundidad a lo largo de todo el siglo XX, parte de esta tendencia se ha visto compensada con una reducción paralela de la mortalidad, y singularmente de la mortalidad infantil, con el correspondiente alargamiento de la vida.

Según la «Encuesta madrileña sobre relaciones familiares», en conjunto y considerando solamente las líneas vertical y horizontal de parentesco, así como la eventual tenencia de cónyuge, la media de familiares propios $^{2}$ (los de la familia de origen junto con los comunes con el cónyuge) que tienen las personas que han respondido a la encuesta se eleva a 
13,2 personas, oscilando entre 3 o menos familiares en un $4 \%$ de los casos y 40 o más en otro $2 \%$ de los casos. El número de miembros que componen la red familiar propia, sin embargo, varía no solamente de un individuo a otro, sino que lo hace principalmente en función de la fase del ciclo de vida en que se encuentre, dependiendo de su proyecto de vida familiar, de los proyectos de vida familiar de los demás miembros que componen su red familiar así como de la inexorabilidad de la muerte. Así, mientras los entrevistados menores de 30 años emancipados tienen una media de 7,7 familiares propios, los mayores de 60 años tienen una media de 21,2 , de suerte que a mayor edad mayor número de familiares tanto propios como políticos.

En la conformación de esta tendencia confluyen distintos factores, coyunturales unos, estructurales otros. Así, por un lado, el número de ascendientes va disminuyendo con la edad y en función de la incidencia de la mortalidad, que -como es sabido- tiene lugar a edades cada vez más avanzadas. Pero estas pérdidas se compensan con la aparición de los descendientes cuando se opta por la formación de un familia, aunque el número de los mismos está disminuyendo entre las nuevas familias. Cuando éstos se hacen mayores y optan por la formación de su propia familia aparecen los nietos. Los hermanos, por otro lado, también tienden en general a formar sus propias familias, con lo que se amplían los miembros de la red familiar por la vía colateral. El diferente tamaño de la red según la fase del ciclo familiar recoge así, por un lado, los efectos del descenso de la fecundidad, pero también los efectos propios del ciclo de vida y de la materialización de los proyectos de vida familiar de los hermanos. El peso que tiene cada uno de los factores no es posible aislarlo cuando se dispone de datos correspondientes a un único momento temporal, como es éste el caso, debido a que ambos procesos se cruzan en todas las fases del ciclo vital. Para aislar los efectos derivados de la caída de la natalidad sería necesario disponer de datos comparables referidos a dos momentos temporales diferentes.

Pero el inicio de un proyecto de vida en común (matrimonial o en pareja) implica también el establecimiento de un vínculo familiar de hecho con la red familiar propia del cónyuge, por lo que la red familiar en la que se encuentran las personas que han optado por un proyecto de vida en común es de hecho mucho mayor. Así, como media para el conjunto de los entrevistados, la diferencia en el número de familiares próximos entre quienes tienen cónyuge frente a quienes no lo tienen es de 6,6 miembros, variando nuevamente de forma apreciable según la fase del ciclo vital en la que se encuentren el entrevistado y los miembros de su familia políti- 
Cambios en las relaciones familiares y en la solidaridad...

ca, aunque también en este caso se cumple la regla de a mayor edad mayor tamaño de la familia política.

TABLA 1A. Número medio de familiares propios vivos del entrevistado y comunes con su cónyuge según su edad y tipo de vinculación familiar

\begin{tabular}{|l|c|c|c|c|c|c|c|c|c|c|c|}
\hline \multicolumn{1}{|c|}{ Edad entrev. } & $\begin{array}{c}\text { Abue- } \\
\text { los }\end{array}$ & Padres & $\begin{array}{c}\text { Herma } \\
\text { nos }\end{array}$ & $\begin{array}{c}\text { Cóny. } \\
\text { De } \\
\text { hnos }\end{array}$ & $\begin{array}{c}\text { Sobri- } \\
\text { nos }\end{array}$ & $\begin{array}{c}\text { Total } \\
\text { fam } \\
\text { pro- } \\
\text { pios }\end{array}$ & $\begin{array}{c}\text { Cónyu } \\
\text { ge }\end{array}$ & Hijos & Nueras & Nietos & $\begin{array}{c}\text { Total } \\
\text { fam } \\
\text { Comu- } \\
\text { nescon } \\
\text { cóny. }\end{array}$ \\
\hline Menor de 30 & 0.8 & 1.7 & 2.0 & 0.9 & 1.3 & 6.7 & 0.6 & 0.3 & 0 & 0 & 1.0 \\
\hline 30 a 39 años & 0.3 & 1.6 & 2.5 & 1.7 & 2.7 & 9.5 & 0.8 & 1.2 & 0 & 0 & 2.0 \\
\hline 40 a 49 años & 0.1 & 1.3 & 2.4 & 1.9 & 3.9 & 10.6 & 0.9 & 2.0 & 0.1 & 0.1 & 3.1 \\
\hline 50 a 59 años & 0 & 0.7 & 2.7 & 2.2 & 6.0 & 12.7 & 0.9 & 2.4 & 0.6 & 0.4 & 4.3 \\
\hline 60 a 65 años & 0 & 0.1 & 2.8 & 2.2 & 6.8 & 13.5 & 0.8 & 2.7 & 1.6 & 2.6 & 7.7 \\
\hline Total & 0.2 & 1.1 & 2.5 & 1.8 & 4.2 & 9.7 & 0.8 & 1.8 & 0.4 & 0.5 & 3.5 \\
\hline
\end{tabular}

TABLA 1B. Número medio de familiares políticos vivos del entrevistado según su edad y tipo de vinculación familiar

\begin{tabular}{|l|c|c|c|c|c|c|c|}
\hline \multicolumn{1}{|c|}{ Edad entrevistado } & $\begin{array}{c}\text { Abuelos } \\
\text { del cony. }\end{array}$ & $\begin{array}{c}\text { Padres del } \\
\text { cóny. }\end{array}$ & $\begin{array}{c}\text { Hnos. del } \\
\text { cóny. }\end{array}$ & $\begin{array}{c}\text { Cóny. de } \\
\text { hnos. del } \\
\text { cóny. }\end{array}$ & Sobrinos & $\begin{array}{c}\text { Total fam. } \\
\text { politicos }\end{array}$ & $\begin{array}{c}\text { Total de } \\
\text { fam.iliares } \\
\text { propios y } \\
\text { políticos }\end{array}$ \\
\hline Menor de 30 & 1.1 & 0.9 & 0.9 & 0.3 & 0.3 & 2.5 & 10.3 \\
\hline 30 a 39 años & 1.4 & 1.3 & 1.7 & 1.1 & 2.0 & 5.5 & 17.0 \\
\hline 40 a 49 años & 1.1 & 1.0 & 2.0 & 1.6 & 3.2 & 6.5 & 20.1 \\
\hline 50 a 59 años & 0.6 & 0.6 & 2.2 & 1.8 & 4.1 & 7.1 & 23.1 \\
\hline 60 a 65 años & 0.1 & 0.1 & 2.0 & 1.6 & 4.0 & 6.1 & 26.8 \\
\hline Total & 0.9 & 0.9 & 1.8 & 1.4 & 2.9 & 7.1 & 19.8 \\
\hline
\end{tabular}

Fuente: G. Meil «Encuesta sobre relaciones familiares en la Comunidad de Madrid».

Por tanto, las personas se encuentran insertas en una amplia red familiar, que puede ir -como media- desde 6 miembros entre quienes no han optado por iniciar un proyecto de vida en común con otra persona hasta 27 entre quienes son ya abuelos, aunque sin haber entrado todavía en la tercera edad. Las personas que realmente carecen de red familiar próxima, consanguínea o política, son casos meramente testimoniales, así como es muy poco frecuente el disponer de una red muy poco numerosa (sólo un 8\% dispone de una red formada por menos de 6 miembros dentro de las categorías consideradas). 
Por otro lado, la prolongación creciente de la vida hace que el número de generaciones que conviven en un momento determinado sea muy superior a lo que podría pensarse a partir de las estadísticas de hogares. Mientras que el número de hogares en el que conviven tres generaciones es muy bajo, particularmente en la Comunidad de Madrid pero también en resto de Comunidades Autónomas (salvo en las de la mitad norte, de Galicia a Cataluña, donde existe tradicionalmente una mayor proporción de este tipo de hogares), no representando en nuestra muestra más que un 5\% del total de hogares, el número de redes familiares próximas de tres generaciones (considerando únicamente la línea vertical de ego o su cónyuge) es, de hecho, la más frecuente, pues dos de cada tres encuestados están insertos en una red compuesta por miembros de tres generaciones distintas. Por otro lado, la coexistencia de cuatro generaciones en alguna fase del ciclo vital no es ni mucho menos infrecuente, dándose principalmente o en la treintena, cuando se pasa a ser padres y todavía vive algún abuelo, o en la cincuentena, cuando se pasa a ser abuelos y todavía vive algún progenitor. La coexistencia de cinco generaciones, por el contrario, es meramente testimonial. Como es fácilmente imaginable, quienes no han optado por formar una familia o no han materializado un proyecto de vida en común son quienes tienen una red familiar con menor número de generaciones, estando integrada por la propia generación de pertenencia y la de los ascendientes.

TABLA 2. Estructura según generaciones de la red familiar del entrevistado o su cónyuge y tipos de hogares en los que vive según el número de generaciones que conviven en el mismo hogar. En porcentajes

\begin{tabular}{|c|c|c|c|c|c|c|c|}
\hline \multicolumn{7}{|c|}{ Nro. de generaciones que componen la red familiar de ego o su cónyuge } & \multirow{2}{*}{$\begin{array}{l}\text { Generaciones } \\
\text { que } \\
\text { viven en el } \\
\text { hogar de ego }\end{array}$} \\
\hline & $\begin{array}{l}\text { Menor de } 30 \\
\text { años }\end{array}$ & $\begin{array}{c}\text { De } 30 \text { a } 39 \\
\text { años }\end{array}$ & $\begin{array}{c}\text { De } 40 \text { a } 49 \\
\text { años }\end{array}$ & $\begin{array}{c}\text { De } 50 \text { a } 59 \\
\text { años }\end{array}$ & $\begin{array}{c}\text { De } 60 \text { a } 65 \\
\text { años }\end{array}$ & Total & \\
\hline 1 generación & 2 & 1 & 0 & 1 & 7 & 2 & 27 \\
\hline 2 generaciones & 34 & 26 & 11 & 20 & 17 & 20 & 68 \\
\hline 3 generaciones & 56 & 54 & 79 & 64 & 65 & 65 & 5 \\
\hline 4 generaciones & 10 & 18 & 10 & 15 & 11 & 13 & 0 \\
\hline 5 generaciones & 0 & 1 & 0 & 0.5 & 0 & 0.3 & 0 \\
\hline Total & 100 & 100 & 100 & 100 & 100 & 100 & 100 \\
\hline $\mathrm{N}$ & 104 & 229 & 256 & 208 & 124 & 921 & 922 \\
\hline
\end{tabular}

Fuente: G. Meil «Encuesta sobre relaciones familiares en la Comunidad de Madrid».

En conjunto, por tanto, la estructura de la red de parentesco se caracteriza por una tendencia hacia la reducción de su tamaño vinculada a 
la reducción del número de hijos de una generación a otra, al tiempo que se alarga la coexistencia de las generaciones, de suerte que la mayor parte de los individuos están insertos a lo largo de su ciclo vitad en una familia compuesta por al menos tres órdenes generacionales, no siendo infrecuente la coexistencia de cuatro generaciones. Si lo queremos expresar mediante un símil vegetal, podemos decir que la estructura de la red familiar se ha transformado desde una forma de «berenjena» (ancha por la base y estrecha por arriba) hacia una estructura más parecida a la de una "vaina de guisante» (estrecha por la base y por arriba). Esta reducción del número de parientes sería, según Reher (1996), una de las características más sobresalientes de la vida familiar en la España de hoy.

El tamaño de la red por sí misma no prejuzga ni la intensidad de las relaciones, ni el tipo de intercambios entre sus miembros. La intensidad de estas relaciones e intercambios está condicionada por multitud de factores, pero el que se evidencia como uno de los más importantes es, sin duda, la distancia geográfica que separa a los miembros de la red de parentesco. A pesar del desarrollo de las nuevas tecnologías y los grandes avances en los medios de comunicación, la accesibilidad está en la base de toda interacción e intercambio de ayuda, de ahí que la distancia a la que vivan los miembros de la red de parentesco y particularmente los que se sienten como más próximos sea de gran importancia (Szydlik, 2000; Logan y Spitze, 1996; Attias-Donfut, 1995; Bien, 1994).

\section{Proximidad residencial}

La norma social dominante para la formación de una familia es la neolocalidad, esto es, que los hijos que deciden iniciar su biografía de pareja, tanto si es por la vía matrimonial como con mayor motivo si lo es a través de una unión de hecho, lo hacen estableciéndose en una vivienda independiente. Solamente en determinadas circunstancias que abordaremos más adelante se inicia la biografía de pareja en la propia vivienda de los padres. El establecimiento de un hogar independiente al de los padres, por otra parte, no necesariamente tiene por qué estar vinculado a la formación de una unidad conyugal, sino que también puede venir determinado bien por el deseo de emancipación de la casa de los padres para vivir solo, una fórmula poco extendida, o más frecuente por motivos de emigración laboral.

Durante la década de los cincuenta, sesenta y primeros años de los setenta España conoció un profundo proceso de recolocación de la población 
en el territorio que implicó a 5,23 millones de personas, que cambiaron su residencia desde las zonas rurales hacia las zonas de fuerte expansión industrial (País Vasco, Cataluña y Madrid), siendo especialmente intenso en la década de los sesenta al absorver la mitad de todo este volúmen de emigración interprovincial. Este proceso migratorio masivo supuso el alejamiento espacial de los miembros de la red de parentesco y especialmente de las generaciones más jóvenes, que en los períodos estivales «volvían al pueblo» a visitar a sus familiares. Este masivo desplazamiento de las generaciones más jóvenes terminó a raíz de la profunda crisis económica y del empleo que se desató a partir de mediados de los setenta y no ha vuelto a repetirse dadas las características de los cambios demográficos, económicos y sociales que ha conocido la sociedad española desde entonces. Esto no significa, sin embargo, que no siga registrándose un "moderado» proceso migratorio desde las regiones económicamente menos dinámicas hacia aquéllas con mayor expansión del empleo, pero, como el nuevo fenómeno de la inmigración extranjera de los países no desarrollados pone de relieve, las condiciones en las que ésta se produce son muy diferentes, teniendo un alcance mucho menor. Así, la Comunidad de Madrid, por ejemplo, sólo ha aumentado su población en un $15,7 \%$ entre 1981 y 2001, cuando sólo en la década de los setenta aumentó un 25\%. Estos patrones de desplazamiento de la población en el espacio tienen gran importancia para la solidaridad familiar, pues, como ya hemos señalado, condicionan decisivamente la accesibilidad a los servicios de ayuda mutua entre los miembros de la red de parentesco y, sobre todo, para aquellas ayudas que suponen servicios personales, tales como, por ejemplo, ayudar en el cuidado de los niños o de los enfermos.

Los datos disponibles sobre Madrid, y a falta de otros datos con una cobertura territorial más amplia, nos indican que el proceso de privatización de los proyectos de vida familiar y la aspiración a una intimidad más distante entre las generaciones, no comporta, salvo en los casos de emigración, un alejamiento espacial de las generaciones y una mayor dispersión de los miembros de la red familiar. Por el contrario, la distancia a la que las nuevas generaciones viven de su red de parentesco parece haberse reducido habida cuenta de la gran ralentización de los procesos migratorios.

Según la encuesta sobre relaciones familiares en la Comunidad de Madrid, la distancia a la que viven la gran mayoría de los padres de los entrevistados no es muy elevada, incluso aunque los entrevistados hayan nacido fuera de la Comunidad de Madrid. Así, sólo un 50\% de los entrevistados que no han nacido en la CAM tienen a sus padres a más de 
Cambios en las relaciones familiares y en la solidaridad...

una hora de distancia en medio de transporte de donde tienen fijado su domicilio y sólo poco más de un tercio (37\%) viven a más de dos horas de distancia (véase Tabla 3). Entre quienes han nacido en la CAM, estas proporciones ascienden únicamente al 11 y $5 \%$ respectivamente. La situación más frecuente entre éstos, por el contrario, es que vivan muy próximos geográficamente, de suerte que casi la mitad vive a menos de 15 minutos a pie de donde viven sus padres $(40 \%$ en otro hogar más un $8 \%$ que viven con el entrevistado), situación frecuente también incluso entre quienes no han nacido en la CAM y tienen algún progenitor vivo (23 más un $8 \%$ respectivamente). Valores no muy diferentes, aunque sí inferiores, se obtienen si se considera la distancia a la que viven los suegros de los entrevistados. Dado que entre los entrevistados hay una mayor proporción de mujeres, esta circunstancia sugiere la hipótesis de que las mujeres tienden a fijar su residencia en mayor medida cerca de sus padres que lo que lo hacen los varones. El sexo del entrevistado, sin embargo y al margen del hecho bien establecido de que los mayores cuando viven con sus hijos tienden a hacerlo con mucha mayor frecuencia en casa de las hijas que de los hijos, no afecta a la distancia a la que se vive de los padres, controlados los efectos del lugar de nacimiento. Las distancias a las que viven los padres y los suegros no presentan diferencias significativas en función del sexo del entrevistado y ello tanto si se consideran todas las categorías de distancias, como si se fija la atención únicamente entre quienes viven en el entorno más próximo. Las mujeres, por tanto, no viven ni más cerca ni más lejos de sus padres que los varones. Esta pauta se evidencia además de una forma muy consistente, pues no sólo se constanta considerando las distancias a las que viven padres y suegros, sino también tomando en consideración la variable edad y generaciones. No sólo no hay diferencias en función de la edad de los entrevistados, sino que los hijos emancipados de los entrevistados tampoco viven más lejos que las hijas emancipadas, como puede observarse en la Tabla 4.

Los datos de la tabla 4 parecen sugerir que entre los hijos de rango segundo, los varones tienden en mayor medida a fijar su residencia más lejos de sus padres e incluso a emigrar fuera de la Comunidad de Madrid que el resto de sus hermanos, pero estos resultados pueden ser meramente casuales y no responder a pauta familiar alguna, no reflejando así reminiscencias de un sistema familiar tradicional ya desaparecido. Los datos evidencian, por tanto, de una forma muy clara que las hijas no tienden a vivir en mayor medida que los hijos varones más cerca de sus padres y ello ni entre las generaciones más jóvenes, ni entre las genera- 
ciones más mayores. Por otro lado, los hijos emancipados de los entrevistados tampoco viven más lejos de lo que viven el conjunto de entrevistados nacidos en la CAM de sus padres. Esto es, las generaciones más jóvenes tienden a vivir tan cerca o tan lejos de sus padres como las generaciones menos jóvenes de los suyos, siempre que no hayan emigrado. Por tanto, no puede afirmarse que el proceso de privatización de los proyectos de vida familiar haya comportado el distanciamiento geográfico de las generaciones, controlados los efectos de la migración, ni que exista tendencia alguna en este sentido. Esta misma conclusión se ve corrobarada por dos encuestas que realizó el autor en 1995 y 2004 a una muestra de madres de hijos menores de 13 años en la corona metropolitana de Madrid: la proporción de mujeres que señalaron que vivían a menos de $1 / 4$ de hora de sus padres (si los tenían) era del 32 y $31 \%$ respectivamente y las que vivían a una distancia de entre $1 / 4$ y $1 / 2$ hora un 21 y $23 \%$, mientras que las que vivían a menos de 1 hora pero a más de $1 / 2$ hora era del 16 y $17 \%$ respectivamente, viviendo el resto (32 y $29 \%$ ) a mayor distancia.

Tabla 3. Proximidad residencial de los ascendientes consanguíneos y políticos según si el entrevistado o su cónyuge, si lo tiene, ha nacido o no en la

Comunidad de Madrid

\begin{tabular}{|l|c|c|c|c|c|c|c|c|c|c|}
\hline & \multicolumn{2}{|c|}{$\begin{array}{c}\text { Abuelos del } \\
\text { entrevistadode }\end{array}$} & \multicolumn{2}{c|}{$\begin{array}{c}\text { Abuelos del } \\
\text { cónyuge de }\end{array}$} & \multicolumn{3}{c|}{$\begin{array}{c}\text { Padres del entrevistado, } \\
\text { nacido en }\end{array}$} & \multicolumn{2}{|c|}{$\begin{array}{c}\text { Padres del cónyuge, } \\
\text { nacido en }\end{array}$} \\
\cline { 2 - 12 } & Madre & Padre & Madre & Padre & $\begin{array}{c}\text { No } \\
\text { CAM }\end{array}$ & CAM & Total & $\begin{array}{c}\text { No } \\
\text { CAM }\end{array}$ & CAM & Total \\
\hline $\begin{array}{l}\text { En casa del entrev. 0 } \\
\text { de los padres }\end{array}$ & 10 & 1 & 4 & 8 & 8 & 8 & 8 & 5 & 3 & 4 \\
\hline Mismo edificio & 3 & 20 & 4 & 0 & 4 & 7 & 5 & 1 & 4 & 3 \\
\hline Menos 15 min. a pie & 23 & 20 & 30 & 8 & 19 & 33 & 26 & 17 & 33 & 25 \\
\hline $\begin{array}{l}\text { Menos 1/2 h. de } \\
\text { transp. }\end{array}$ & 18 & 19 & 19 & 16 & 10 & 26 & 18 & 14 & 22 & 18 \\
\hline $\begin{array}{l}\text { De 1/2 a 1 h. de } \\
\text { transp. }\end{array}$ & 8 & 19 & 15 & 12 & 10 & 15 & 13 & 8 & 20 & 14 \\
\hline De 1 a 2 h. de transp. & 7 & 10 & 4 & 16 & 12 & 6 & 9 & 14 & 11 & 13 \\
\hline Más lejos & 31 & 29 & 26 & 40 & 37 & 5 & 21 & 40 & 7 & 24 \\
\hline Total & 100 & 100 & 100 & 100 & 100 & 100 & 100 & 100 & 100 & 100 \\
\hline N & 77 & 59 & 27 & 25 & 337 & 320 & 658 & 254 & 242 & 496 \\
\hline
\end{tabular}

Fuente: G. Meil «Encuesta sobre relaciones familiares en la Comunidad de Madrid». 
Cambios en las relaciones familiares y en la solidaridad...

TABLA 4. Distancia a la que viven los hijos emancipados de los entrevistados según su sexo y su rango

\begin{tabular}{|l|c|c|c|c|c|c|c|}
\hline & \multicolumn{3}{|c|}{ Hijo mayor } & \multicolumn{3}{c|}{ Hijo 2 $^{\circ}$} & ${\text { Hijo } 3^{\circ}}^{\circ}$ \\
\cline { 2 - 8 } & Varón & Mujer & Total & Varón & Mujer & Total & Total \\
\hline Mismo edificio & 4 & 4 & 4 & 1 & 3 & 2 & 2 \\
\hline Menos 15 min. a pie & 29 & 34 & 32 & 28 & 39 & 33 & 31 \\
\hline Menos 1/2 h. de transp. & 30 & 31 & 30 & 27 & 20 & 24 & 28 \\
\hline De 1/2 a 1 h. de transp. & 15 & 15 & 13 & 13 & 16 & 14 & 13 \\
\hline De 1 a 2 h. de transp. & 7 & 2 & 4 & 10 & 10 & 10 & 8 \\
\hline Más lejos & 14 & 15 & 15 & 21 & 12 & 17 & 18 \\
\hline Total & 100 & 100 & 100 & 100 & 100 & 100 & 100 \\
\hline N & 99 & 108 & 207 & 78 & 61 & 139 & 67 \\
\hline
\end{tabular}

Fuente: G. Meil «Encuesta sobre relaciones familiares en la Comunidad de Madrid».

TABLA 5. Proximidad residencial de los familiares colaterales.

Porcentaje de hermanos/as y hermanos/as del cónyuge que vive a menos de 15 minutos a pie y a menos de media hora de transporte del entrevistado

\begin{tabular}{|c|c|c|c|c|c|c|c|c|}
\hline & \multicolumn{4}{|c|}{ Nacido en la CAM } & \multicolumn{4}{|c|}{ No nacido en la CAM } \\
\hline & \multicolumn{2}{|c|}{ Hermanos/as a } & \multicolumn{2}{|c|}{ Cuñados/as a } & \multicolumn{2}{|c|}{ Hermanos/as a } & \multicolumn{2}{|c|}{ Cuñados/as a } \\
\hline & $\begin{array}{l}\text { Menos } \\
15 \text { min. }\end{array}$ & $\begin{array}{c}\text { Menos } \\
1 / 2 \mathrm{~h}^{*}\end{array}$ & $\begin{array}{l}\text { Menos } \\
15 \text { min. }\end{array}$ & $\begin{array}{c}\text { Menos } \\
1 / 2 \mathbf{h}^{*}\end{array}$ & $\begin{array}{l}\text { Menos } \\
15 \text { min. }\end{array}$ & $\begin{array}{c}\text { Menos } 1 / 2 \\
\text { h. }^{*}\end{array}$ & $\begin{array}{l}\text { Menos } \\
15 \text { min. }\end{array}$ & $\begin{array}{c}\text { Menos } \\
1 / 2 \text { h. }^{*}\end{array}$ \\
\hline Ninguno & 63 & 30 & 66 & 36 & 72 & 51 & 73 & 53 \\
\hline La mitad o menos & 18 & 19 & 13 & 15 & 14 & 19 & 13 & 15 \\
\hline Más de la mitad & 2 & 7 & 2 & 6 & 5 & 9 & 3 & 9 \\
\hline Todos & 17 & 44 & 19 & 43 & 9 & 21 & 11 & 23 \\
\hline Total & 100 & 100 & 100 & 100 & 100 & 100 & 100 & 100 \\
\hline $\mathrm{N}$ & 323 & 323 & 251 & 251 & 435 & 435 & 337 & 337 \\
\hline
\end{tabular}

* Incluye también a los que viven a menos de 15 minutos a pie.

Fuente: G. Meil «Encuesta sobre relaciones familiares en la Comunidad de Madrid».

Dada esta tendencia a vivir cerca de los progenitores también es probable que no se viva muy alejado de los hermanos o de los hermanos del cónyuge, sobre todo si no se ha migrado, aunque sea más frecuente vivir cerca de alguno de los ascendientes que de los hermanos. Consecuencia de estas pautas residenciales, es la presencia de al menos un familiar consanguíneo o político en las inmediaciones y varios en un radio de distancia de menos de media hora de transporte. Así, un tercio de todos los entrevistados tienen a dos o más familiares a menos de 15 minutos a pie de donde viven y tres de cada cuatro de los que han nacido en Madrid tienen a más de dos en un radio de media hora (véase tablas 5 y 6). Para comprender estas pautas residenciales es preciso tomar en consideración, no sólo motivos familiares sino también otros de carácter social, pues el lugar donde viven los padres es también el contexto geográficosocial en el que se ha vivido durante la juventud y donde se han trabado 
amistades y se ha adquirido la identidad social, por lo que no debe resultar extraño que se desee también residir como adulto en el mismo espacio.

TABla 6. Número total de familiares consanguíneos o políticos que viven en las inmediaciones del entrevistado según haya nacido o no en la Comunidad de Madrid

\begin{tabular}{|l|c|c|c|c|c|c|}
\hline \multirow{2}{*}{} & \multicolumn{3}{|c|}{ A menos 15 minutos a pie } & \multicolumn{3}{c|}{$\begin{array}{c}\text { A menos de } 1 / 2 \text { hora de } \\
\text { transporte* }\end{array}$} \\
\cline { 2 - 7 } & No CAM & CAM & Total & No CAM & CAM & Total \\
\hline Ninguno & 43 & 32 & 38 & 27 & 13 & 20 \\
\hline Uno & 22 & 30 & 26 & 17 & 16 & 17 \\
\hline Dos & 16 & 14 & 15 & 15 & 20 & 17 \\
\hline Tres & 10 & 11 & 10 & 14 & 17 & 16 \\
\hline Cuatro & 4 & 5 & 4 & 10 & 11 & 10 \\
\hline Cinco & 3 & 4 & 4 & 5 & 10 & 7 \\
\hline Más de cinco & 2 & 4 & 3 & 12 & 13 & 13 \\
\hline Total & 100 & 100 & 100 & 100 & 100 & 100 \\
\hline N & 496 & 420 & 917 & 496 & 420 & 917 \\
\hline
\end{tabular}

* Incluye también a los que viven a menos de 15 minutos a pie.

Fuente: G. Meil «Encuesta sobre relaciones familiares en la Comunidad de Madrid».

\section{Frecuencia de relaciones}

La proximidad propicia el contacto, como ya se ha señalado, y de hecho la vida familiar en España, en general, y en Madrid, en particular, se caracteriza por un elevado grado de contacto con los familiares, contacto que es de carácter personal además de telefónico. Ocho de cada diez entrevistados ve al menos a un familiar consanguíneo o político una o más veces a la semana para pasar un rato juntos, siendo más frecuentes los contactos personales dentro de la línea vertical, ya sean padres ( $84 \%$ si el entrevistado ha nacido en la CAM) o hijos emancipados (78\% con el hijo mayor emancipado), que con miembros de la línea horizontal (61\% con alguno de los hermanos y $43 \%$ a los hermanos del cónyuge, entre los que han nacido en la CAM), al menos entre los entrevistados que no han migrado, atenuándose sustancialmente las diferencias cuando se toman en consideración los procesos migratorios. No obstante, las relaciones familiares no se caracterizan por una verticalidad excesivamente acentuada, llamando la atención el elevado grado de contacto personal que se tiene también con los hermanos: tres de cada cuatro entrevistados, independientemente de dónde hayan nacido, ven a alguno de sus hermanos al menos una vez al mes y casi la mitad de los entrevistados nacidos en la CAM ven a todos sus hermanos semanalmente. 


\section{Cambios en las relaciones familiares y en la solidaridad...}

TABLA 7. Frecuencia de visitas para pasar un rato juntos con los ascendientes consanguíneos y políticos con los que no se convive, según si el entrevistado o su cónyuge, si lo tiene, haya nacido o no en la Comunidad de Madrid

\begin{tabular}{|l|c|c|c|c|c|c|c|c|c|c|}
\hline & $\begin{array}{c}\text { Abuelos del } \\
\text { entrevistado de }\end{array}$ & \multicolumn{2}{|c|}{$\begin{array}{c}\text { Abuelos del } \\
\text { cónyuge de }\end{array}$} & \multicolumn{2}{c|}{$\begin{array}{c}\text { Padres del entrevistado, } \\
\text { nacido en }\end{array}$} & \multicolumn{3}{c|}{$\begin{array}{c}\text { Padres del cónyuge, } \\
\text { nacido en }\end{array}$} \\
\cline { 2 - 14 } & Madre & Padre & Madre & Padre & $\begin{array}{c}\text { No } \\
\text { CAM }\end{array}$ & CAM & Total & $\begin{array}{c}\text { No } \\
\text { CAM }\end{array}$ & CAM & Total \\
\hline Diariamente & 12 & 7 & 12 & 0 & 18 & 31 & 24 & 6 & 14 & 10 \\
\hline $\begin{array}{l}\text { Varias veces la } \\
\text { semana }\end{array}$ & 17 & 12 & 15 & 4 & 14 & 28 & 21 & 12 & 21 & 17 \\
\hline Una vez por semana & 12 & 17 & 0 & 39 & 15 & 24 & 19 & 17 & 27 & 22 \\
\hline $\begin{array}{l}\text { Un par de veces al } \\
\text { mes }\end{array}$ & 23 & 20 & 35 & 30 & 20 & 12 & 16 & 29 & 27 & 28 \\
\hline Varias veces al año & 25 & 25 & 19 & 26 & 22 & 4 & 13 & 23 & 10 & 17 \\
\hline $\begin{array}{l}\text { Con menor } \\
\text { frecuencia }\end{array}$ & 12 & 19 & 19 & 23 & 11 & 1 & 6 & 13 & 2 & 7 \\
\hline Total & 100 & 100 & 100 & 100 & 100 & 100 & 100 & 100 & 100 & 100 \\
\hline N & 69 & 59 & 26 & 23 & 333 & 315 & 648 & 239 & 236 & 475 \\
\hline
\end{tabular}

Fuente: G. Meil «Encuesta sobre relaciones familiares en la Comunidad de Madrid».

En principio podría pensarse que esta elevada frecuencia de contactos funciona mientras vivan los padres, quienes aglutinarían a los hijos en torno suyo en las visitas de los fines de semana, para debilitarse sustancialmente una vez que los padres han muerto. La frecuencia de contactos con los hermanos no varía, sin embargo, en función de si la madre vive o no, sino que depende casi en excluividad de la proximidad geográfica, de forma que el contacto es frecuente si viven en las inmediaciones, para hacerse más esporádico si viven alejados ${ }^{3}$. Por otra parte, los contactos son más frecuentes con los familiares consanguíneos que con los políticos, incluso entre los varones, conclusión que se deriva tanto de las respuestas dadas a la frecuencia de contactos con las distintas categorías de familiares, como de las respuestas dadas a la pregunta si ven más a familiares consanguíneos o a familiares políticos. No obstante, los varones tienden a afirmar en mayor medida que las mujeres que ven ambas líneas con igual frecuencia.

Como es sabido, la dedicación y el empeño en mantener activo y fluido el contacto con los familiares no es igual entre los hombres que entre las mujeres. Las mujeres tienden a ver con bastante mayor frecuencia a miembros de su familia consanguínea que los varones. Controlados los efectos de la distancia a la que viven así como si han migrado, las mujeres ven con mucha mayor frecuencia a sus padres que los varones, además de ver con mucha mayor frecuencia a sus padres que a sus sue- 
gros. Mientras dos de cada tres mujeres nacidas en la CAM afirman ver a sus padres diariamente, sólo uno de cada cuatro entrevistados varones ve a los suyos con igual frecuencia. Por otro lado, las mujeres también ven con mayor frecuencia a sus hermanos, particularmente si son hermanas, así como a sus abuelos maternos que los varones, aunque no así a los abuelos paternos, lo que no es sino también un reflejo del papel de las mujeres como mediadoras en el sistema de parentesco (kinkeepers). No obstante, y a pesar de la mayor inversión de tiempo y energía de las mujeres en las relaciones con sus familiares que los varones, la frecuencia de contacto de éstos con sus familiares es indudablemente elevada, lo que no significa que la intensidad y proximidad afectiva sean similares: de los varones nacidos en la CAM con padres o hermanos vivos, tres de cada cuatro varones afirman ver a sus padres una o más veces a la semana y uno de cada dos afirma ver al menos a un hermano con igual frecuencia.

El contacto telefónico con los miembros de la red de parentesco es algo más frecuente que las visitas personales, particularmente el contacto con los padres cuando se ha migrado, pero el recurso al teléfono y las visitas personales lejos de funcionar como sustitutos el uno del otro, se refuerzan mutuamente. Quienes ven a sus familiares con frecuencia también hablan con frecuencia con ellos por teléfono, mientras que quienes los ven con menor frecuencia tienden también a hablar con ellos más esporádicamente. Así, algo más del $50 \%$ de las mujeres que afirman ver a su madre varias veces a la semana o diariamente hablan con igual frecuencia por teléfono con ella, mientras que quienes la ven un par de veces al año tienden a hablar semanalmente o varias veces al mes con ella por teléfono. Esta relación es especialmente fuerte en los contactos entre los hermanos, más que en las relaciones entre las generaciones, donde el recurso al teléfono sirve para compensar un menor contacto personal, sobre todo, cuando media una mayor distancia geográfica entre las generaciones. Al igual que sucede con las visitas personales, las mujeres hablan por teléfono con mucha mayor frecuencia con familiares que los hombres y es que además de invertir más en las relaciones sociales, las mujeres tienden a elegir entre sus confidentes para expresar sus preocupaciones y buscar soluciones a sus problemas (o a los problemas familiares) a miembros de la red familiar antes que a miembros fuera de ella, particularmente cuando ya han formado una familia. Así, es la madre o una de las hermanas a quien se suele buscar para consultar, comentar o participar de la multitud de alegrías y preocupaciones que el día a día va deparando en todos los planos de la vida cotidiana, sin que ello signifique 
que no se haga partícipe de las mismas al cónyuge, amigas u otras personas. Los varones, por el contrario, más reservados en general (así como menos implicados en los problemas familiares del día a día), cuando buscan a alguien a quien confiar sus preocupaciones o sus proyectos, más allá del cónyuge, suelen preferir, por el contrario, a amigos antes que a familiares.

TABLA 8. Frecuencia de visitas para pasar un rato juntos con los hijos emancipados de los entrevistados según su sexo y su rango

\begin{tabular}{|l|c|c|c|c|c|c|c|}
\hline & \multicolumn{3}{|c|}{ Hijo mayor } & \multicolumn{3}{c|}{ Hijo 2 $^{\circ}$} & Hijo 3 $^{\circ}$ \\
\cline { 2 - 8 } & Varón & Mujer & Total & Varón & Mujer & Total & Total $^{\circ}$ \\
\hline Diariamente & 25 & 31 & 28 & 19 & 33 & 25 & 17 \\
\hline $\begin{array}{l}\text { Varias veces la } \\
\text { semana }\end{array}$ & 29 & 30 & 30 & 23 & 30 & 26 & 29 \\
\hline Una vez por semana & 21 & 18 & 19 & 23 & 16 & 20 & 21 \\
\hline $\begin{array}{l}\text { Un par de veces al } \\
\text { mes }\end{array}$ & 12 & 8 & 10 & 22 & 8 & 16 & 15 \\
\hline Varias veces al año & 5 & 8 & 7 & 6 & 12 & 9 & 12 \\
\hline Con menor frecuencia & 7 & 6 & 6 & 6 & 2 & 4 & 6 \\
\hline Total & 100 & 100 & 100 & 100 & 100 & 100 & 100 \\
\hline N & 99 & 108 & 207 & 78 & 61 & 139 & 67 \\
\hline
\end{tabular}

Fuente: G. Meil «Encuesta sobre relaciones familiares en la Comunidad de Madrid».

La frecuencia de contactos personales con familiares más alejados tiende a ser, por el contrario, mayormente esporádica. Así, un tercio de los entrevistados $(37 \%)$ ven al menos varias veces al año a los tíos que con mayor frecuencia ven, aunque los que declaran no ver nunca a ninguno (teniéndolos) se eleva sólo al $20 \%$, siendo el contacto menos frecuente en las zonas urbanas que en los pueblos. El contacto con los primos no está mucho más extendido, ni tampoco es más frecuente que con los tíos (40 y $15 \%$ respectivamente), disminuyendo además con la edad. Las relaciones con los parientes más alejados no desaparecen, por tanto, pero sí se hacen esporádicas, sobre todo en los contextos más urbanizados, lo cual está en relación no sólo con la distancia geográfica a la que viven sino, sobre todo, con la "distancia afectiva". Por lo que se refiere a la variable sexo, mientras el contacto con tíos es algo más frecuente entre las mujeres que entre los varones, en el caso de los primos las diferencias no son significativas. Los contactos familiares regulares se centran, por tanto, fundamentalmente dentro del círculo familiar más próximo integrado por los miembros de la familia nuclear de origen (padres, hijos y hermanos) y sólo en los nú- 
cleos menos urbanizados incluye con mayor frecuencia a miembros más alejados en la línea de parentesco. En los ritos de tránsito, tales como los bautizos, bodas, funerales o comuniones, por el contrario, la pauta dominante es la de la reactivación de los lazos simbólicos de pertenencia a «la familia», sin que ello comporte, sin embargo, una sociabilidad elevada entre celebración y celebración, ni se traduzca, como veremos más adelante, en intercambios de ayuda mutua.

Comparativemente con los amigos, la utilización del tiempo libre y de ocio en el contexto familiar tiende a crecer según se avanza en el ciclo familiar: cuando no hay pareja (pero sí independencia residencial) o no hay hijos, el tiempo de ocio se realiza más con los amigos antes que con familiares; cuando aparecen los hijos tiende a focalizarse en mayor medida con miembros de la familia, en especial con los padres y ello además en todas las clases sociales, por tanto, tanto entre los trabajadores como entre los profesionales. A medida que los hijos van haciéndose mayores, esta orientación preferente hacia la familia se refuerza, lo que no significa que se deje de tener contactos más o menos frecuentes o espaciados, según las circunstancias, con amigos. Los lazos familiares se reproducen y se refuerzan así a través de las generaciones con los niños como principales mediadores familiares. En este sentido «la visita a los abuelos» supone un importantísimo cemento social para las redes de parentesco, aunque, como hemos señalado anteriormente, los abuelos y singularmente la abuela no constituyen el único polo de atracción para los miembros de la red familiar, por más que en determinadas fases del ciclo de vida familiar ocupen un lugar central en la articulación de la sociabilidad familiar.

TABLA 9. Con quién diría usted que pasa más tiempo libre y de ocio, ¿con la familia o con los amigos?, respuestas según la fase del ciclo familiar

\begin{tabular}{|l|c|c|c|c|c|c|c|c|}
\hline & $\begin{array}{c}\text { Sin } \\
\text { cóny. ni } \\
\text { hijos }\end{array}$ & $\begin{array}{c}\text { Con } \\
\text { cony. } \\
\text { Sin hijos }\end{array}$ & $\begin{array}{c}\text { Hijo } \\
\text { mayor 0 } \\
\text { a 2 años }\end{array}$ & $\begin{array}{c}\text { Hijo } \\
\text { mayor 3 a } \\
\text { 17 años }\end{array}$ & $\begin{array}{c}\text { Hijo } \\
\text { mayor } \\
\mathbf{1 8} \text { a 29 } \\
\text { años }\end{array}$ & $\begin{array}{c}\text { Hijo } \\
\text { mayor } \\
\text { de 30 } \\
\text { o más }\end{array}$ & $\begin{array}{c}\text { Hijo } \\
\text { mayor } \\
\text { no } \\
\text { convive }\end{array}$ & Total \\
\hline Con la familia & 21 & 36 & 55 & 66 & 62 & 74 & 75 & 59 \\
\hline Más o menos igual & 20 & 25 & 27 & 18 & 19 & 4 & 13 & 18 \\
\hline Con los amigos & 59 & 40 & 18 & 17 & 19 & 22 & 12 & 24 \\
\hline Total & 100 & 100 & 100 & 100 & 100 & 100 & 100 & 100 \\
\hline $\mathrm{N}$ & 86 & 101 & 33 & 200 & 247 & 23 & 202 & 892 \\
\hline
\end{tabular}

Fuente: G. Meil «Encuesta sobre relaciones familiares en la Comunidad de Madrid». 
Cambios en las relaciones familiares y en la solidaridad...

\section{Conflictos familiares}

Esta elevada frecuencia de contactos sugiere una buena relación entre los miembros de la red familiar y así es también en la gran mayoría de los casos, lo que no significa, sin embargo, que las relaciones con la familia, dada la centralidad que ocupan en el sistema de relaciones sociales de los individuos, no sean también fuente de desavenencias más o menos espaciadas en el tiempo tanto entre los cónyuges, como con los miembros de la red de parentesco, desavenencias que pueden transformarse en conflictos más o menos agudos, llegando incluso en ocasiones a escalar hasta el recurso a la violencia, física o psíquica, o, sin llegar a dichos extremos, hasta la ruptura de las relaciones.

En efecto y al margen de la violencia familiar, que no podemos abordar aquí, las relaciones con la familia se encuentran entre uno de los temas más frecuentes de desavenencias entre los cónyuges (Meil, 1999: 164 y ss). Junto con la división de las tareas domésticas y el cuidado de los niños, las relaciones con la familia es uno de los temas que con cierta recurrencia suelen enfrentar a marido y mujer, por delante incluso de las desavenencias por temas de dinero o de las muy inusuales desavenencias por motivos ideológicos. Estas desavenencias se dan sobre todo cuando los cónyuges son más jóvenes y se encuentran en la fase de crianza de los niños, en la que tienen que afirmar su autoridad y su modelo educativo frente a lo que se interpreta como «injerencias» de los demás miembros de la red. Estos conflictos suelen referirse en general a los padres de uno u otro cónyuge, por lo que a medida que los niños se van haciendo mayores y aquéllos van muriendo, las desavencias conyugales por temas de familia se hacen, salvo excepciones, infrecuentes.

Las desavenencias por temas familiares no se limitan al núcleo conyugal, sino que suelen implicar también desavenencias con los miembros de la red de parentesco. Estas desavenencias pueden ser de muy distinto grado y alcance, pero no son ni mucho menos infrecuentes, incluso las más acaloradas no son del todo raras en las biografías de las personas. Así, en la «Encuesta sobre relaciones familiares de la CAM», uno de cada cinco encuestados ( $22 \%$ ) ha mantenido una discusión agria y acalorada con algún miembro de su red de parentesco, no habiendo diferencias significativas en función del sexo, por lo que las han experimentado con igual frecuencia hombres y mujeres. Estos enfrentamientos verbales elevados de tono se dan, sobre todo, con la familia consanguínea y particularmente en las relaciones padres-hijos, ya sea con los padres mayores, o con los hijos ya adultos, o bien con uno de los hermanos o hermanas. Así, 
uno de cada dos entrevistados que ha discutido agria y acaloradamente con algún familiar lo ha hecho con su padre o su madre y uno de cada tres lo ha hecho con algún hijo. Los enfrentamientos verbales agudos con la familia política son poco frecuentes (sólo un 15\% de los que han discutido agria y acaloradamente con algún familiar lo han hecho con los suegros y sólo un $8 \%$ lo han hecho con los hermanos del cónyuge), lo que no puede interpretarse como una mejor relación con los allegados que con los consanguíneos, sino como signo de un mayor distanciamiento emocional, menor proximidad afectiva y mayor sujeción de estas relaciones a las normas sociales más formalizadas.

Estas desavenencias con la red familiar se tornan en ocasiones especialmente vejatorias y así algo menos de uno de cada diez entrevistados ha sido insultado, despreciado o ridiculizado reiteradamente por un familiar, afectando por igual a varones y a mujeres. Este tipo de relaciones tan negativas se da nuevamente con mayor frecuencia entre los familiares consanguíneos directos antes que con los familiares políticos, procediendo en mayor medida de miembros varones antes que femeninos (padre o hermanos varones), tal como sucede también en las demás dimensiones de los malos tratos en el espacio doméstico.

TABLA 10. Desavenencias entre los miembros de la red familiar.

Porcentaje de entrevistados que afirman haber tenido conflictos en alguna ocasión con alguna de las categorías consideradas

\begin{tabular}{|l|c|c|c|c|c|c|c|c|c|}
\hline & \multicolumn{3}{|c|}{$\begin{array}{c}\text { Ha discutido acalorada y } \\
\text { agriamente con }\end{array}$} & \multicolumn{3}{c|}{$\begin{array}{c}\text { Ha recibido insultos, } \\
\text { desprecio o ha sido } \\
\text { ridiculizado por }\end{array}$} & \multicolumn{3}{|c|}{ No se habla con } \\
\cline { 2 - 11 } & Mujer & Varón & Total & Mujer & Varón & Total & Mujer & Varón & Total \\
\hline Con familiares & 30 & 32 & 31 & 8 & 12 & 9 & 15 & 10 & 13 \\
\hline Con no familiares & 8 & 12 & 9 & 4 & 6 & 5 & 5 & 8 & 6 \\
\hline Con nadie & 75 & 71 & 74 & 90 & 86 & 89 & 84 & 83 & 84 \\
\hline Total* & 113 & 115 & 114 & 102 & 104 & 103 & 104 & 101 & 103 \\
\hline $\mathrm{N}$ & 594 & 326 & 920 & 594 & 326 & 920 & 588 & 323 & 911 \\
\hline
\end{tabular}

* Suma más de 100 porque existían hasta tres posibles respuestas.

La ruptura total de relaciones con algún miembro de la red de parentesco tampoco es ni mucho menos un hecho infrecuente, pues hay un $11 \%$ de los entrevistados que afirman no hablarse con algún miembro de la familia. Esta ruptura de relaciones se da con mayor frecuencia entre los colaterales que con los ascendientes e incluso es más frecuente una ruptura con los hermanos o cuñados 'que con los suegros: es el conocido odio entre hermanos. Así, un $28 \%$ de los que no se hablan con algún familiar 
Cambios en las relaciones familiares y en la solidaridad...

no lo hacen con alguno de sus hermanos, un $25 \%$ no se habla con algún cuñado y un $12 \%$ no lo hace con alguno de los hermanos del cónyuge frente a un $17 \%$ que no se habla con sus padres, un $10 \%$ que no se habla con los suegros y un $3 \%$ que no se habla con alguno de sus hijos.

TABLA 11. Desavenencias con familiares. Categorias de parentesco con las que han tenido conflictos los entrevistados que afirman tener desavenencias con familiares. En porcentajes

\begin{tabular}{|l|c|c|c|c|c|c|c|c|c|}
\hline & \multicolumn{3}{|c|}{$\begin{array}{c}\text { Ha discutido acalorada y } \\
\text { agriamente con }\end{array}$} & \multicolumn{2}{c|}{$\begin{array}{c}\text { Ha recibido insultos, } \\
\text { desprecio o ha sido } \\
\text { ridiculizado por }\end{array}$} & \multicolumn{3}{c|}{ No se habla con } \\
\cline { 2 - 12 } & Mujer & Varón & Total & Mujer & Varón & Total & Mujer & Varón & Total \\
\hline Padre & 17 & 32 & 22 & 7 & 25 & 15 & 8 & 12 & 9 \\
\hline Madre & 23 & 29 & 25 & 5 & 18 & 10 & 5 & 15 & 8 \\
\hline Hermanos & 24 & 23 & 22 & 25 & 32 & 28 & 28 & 27 & 28 \\
\hline Hermanas & 18 & 17 & 18 & 18 & 21 & 19 & 9 & 12 & 10 \\
\hline Hijos & 18 & 13 & 16 & 10 & 7 & 9 & 0 & 0 & 2 \\
\hline Hijas & 21 & 7 & 16 & 7 & 0 & 6 & 0 & 0 & 1 \\
\hline Abuelos & 0 & 0 & 0 & 0 & 0 & 0 & 0 & 0 & 0 \\
\hline Tíos & 0 & 0 & 0 & 0 & 0 & 0 & 9 & 12 & 10 \\
\hline Suegros & 11 & 19 & 14 & 15 & 14 & 15 & 9 & 12 & 10 \\
\hline Hnos. del cónyuge & 5 & 4 & 4 & 5 & 7 & 6 & 14 & 6 & 11 \\
\hline Hnas. del cónyuge & 4 & 4 & 4 & 5 & 7 & 6 & 14 & 6 & 11 \\
\hline Cuñados & 8 & 12 & 9 & 15 & 10 & 13 & 31 & 12 & 25 \\
\hline Otros familiares & 0 & 0 & 1 & 0 & 0 & 6 & 0 & 0 & 5 \\
\hline total & 149 & 160 & 151 & 112 & 141 & 133 & 127 & 114 & 130 \\
\hline N & 126 & 69 & 195 & 40 & 28 & 68 & 64 & 34 & 98 \\
\hline
\end{tabular}

* Suma más de 100 porque existían hasta tres posibles respuestas.

Fuente: G. Meil «Encuesta sobre relaciones familiares en la Comunidad de Madrid».

Sin que se llegue al enfrentamiento, otra forma de debilitamiento de las relaciones de parentesco es el espaciamiento en los contactos hasta hacerlos esporádicos. En la inmensa mayoría de los casos, la frecuencia de contactos con los miembros más próximos de la red de parentesco con los que no se vive tiene lugar por lo menos una o varias veces al año. Hay casos, no obstante, en los que la frecuencia de contactos es menor y ello viene determinado fundamentalmente por la distancia a la que viven los allegados. Las categorías de parentesco en las que esta situación se da con más frecuencia son abuelos (un 18\% de los entrevistados con abuelos vivos los ven con una frecuencia menor que la anual), hermanos (11\%), suegros $(8 \%)$, padres $(6 \%)$ e hijos emancipados $(7 \%)$, debiéndose en la 
gran mayoría de los casos (salvo en el caso de los progenitores) a que viven en lugares alejados.

En este contexto conviene llamar la atención sobre el escaso alcance de la imagen popularmente negativa que tienen las relaciones con los suegros. Aunque las relaciones con los suegros se valoran más bajo que las relaciones con los padres (véase tabla 12), los distintos indicadores de conflicto que hemos utilizado no muestran una mayor conflictividad con los suegros que con los padres, ni por parte de los varones ni por parte de las mujeres. Por el contrario, como queda patente en los párrafos anteriores, los conflictos más intensos se dan entre los familiares consanguíneos antes que con los políticos.

TABLA 12. Valoración de las relaciones con los ascendientes. Nota media en una escala de 0 a 10

\begin{tabular}{|l|c|c|}
\hline & Varones & Mujeres \\
\hline Valoración de las relaciones con el padre & 8.1 & 8.6 \\
\hline Valoración de las relaciones con la madre & 8.5 & 8.9 \\
\hline Valoración de las relaciones con el suegro & 7.8 & 7.7 \\
\hline Valoración de las relaciones con la suegra & 7.7 & 7.7 \\
\hline
\end{tabular}

Fuente: G. Meil «Encuesta sobre relaciones familiares en la Comunidad de Madrid».

\section{La familia como fuente de ayudas en caso de necesidad}

\section{La convivencia de las generaciones}

Una de las manifestaciones más tradicionales de la importancia de la solidaridad familiar entre las generaciones ha sido la de facilitar un espacio en la vivienda para afrontar situaciones de necesidad en determinados momentos o en determinadas circunstancias del ciclo de vida. Este ha sido el caso del cuidado de los mayores en casa de los hijos o de los propios mayores, el inicio de la biografía de familia en el hogar de los padres antes de acceder a una vivienda independiente o el acogimiento temporal de algún miembro de la familia que se ha desplazado a la ciudad bien en busca de trabajo o para estudiar. Aunque en el pasado la familia española no se ha caracterizado por ser una familia extensa en la que era frecuente la conviviencia de tres generaciones en un mismo hogar o la convivencia con otros parientes ajenos al núcleo conyugal (de Pablo, 1976; del Campo y Navarro, 1985; Reher, 1996), sino que el modelo de fa- 
Cambios en las relaciones familiares y en la solidaridad...

milia nuclear ha sido siempre dominante, comparativamente con los demás países de la Unión Europea, España se ha caracterizado y continúa caracterizándose por una elevada proporción de hogares complejos formados por más categorías que el cónyuge y los hijos así como por una elevada proporción de hogares formados por el núcleo conyugal y los hijos adultos. Esto quiere decir que lo que podemos llamar «solidaridad residencial» continúa jugando un papel muy importante en la sociedad española. ¿Quiénes son los principales beneficiarios de esta solidaridad residencial de las familias españolas? Tres son las situaciones en el ciclo de vida en las que la solidaridad residencial juega un papel importante para los beneficiarios, aunque tienden a generar con cierta frecuencia situaciones de insatisfacción y estrés entre los implicados:

- Jóvenes adultos antes de iniciar su biografía familiar

- Jóvenes que han iniciado su biografía familiar pero sin recursos suficientes para emanciparse

- Mayores que ya no pueden vivir solos

TABLA 13. Jóvenes conviviendo con sus padres en los países de la UE.

En porcentajes

\begin{tabular}{|l|c|c|c|c|}
\hline \multirow{2}{*}{} & \multicolumn{2}{|c|}{ 20-24 años } & \multicolumn{2}{c|}{ 25-29 años } \\
\cline { 2 - 5 } & $\mathbf{1 9 8 7}$ & $\mathbf{1 9 9 6}$ & $\mathbf{1 9 8 7}$ & $\mathbf{1 9 9 6}$ \\
\hline Alemania & 57 & 53 & 20 & 20 \\
\hline Austria & - & 66 & - & 31 \\
\hline Bélgica & 63 & 69 & 19 & 25 \\
\hline España & 84 & 90 & 49 & 62 \\
\hline Finlandia & - & 24 & - & 8 \\
\hline Francia & 47 & 52 & 14 & 18 \\
\hline Grecia & 63 & 73 & 39 & 50 \\
\hline Irlanda & 64 & 60 & 28 & 34 \\
\hline Italia & 81 & 89 & 39 & 59 \\
\hline Luxemburgo & 64 & 64 & 26 & 30 \\
\hline Países Bajos & 55 & 51 & 15 & 14 \\
\hline Portugal & 75 & 80 & 39 & 52 \\
\hline Reino Unido & 45 & $\mathbf{5 7}$ & 15 & 17 \\
\hline
\end{tabular}

Leyenda: La diferencia de cada valor hasta 100 es la proporción de jóvenes que no conviven con sus padres en el mismo hogar.

Fuente: L. Moreno (2000): Ciudadanos precarios, Ariel, Barcelona, p. 99

En primer lugar se encuentran los jóvenes adultos, que desde la década de los ochenta han ido postponiendo cada vez más en el tiempo su salida del hogar de los padres para constituir un hogar independiente. Si 
desde los años sesenta hasta comienzos de los ochenta los jóvenes se han ido emancipando cada vez más temprano hasta alcanzar un mínimo a comienzos de los ochenta, a partir de entonces el proceso se ha ido invirtiendo y cada vez se emancipan del hogar paterno más tarde. Dada la escasa incidencia de la experiencia de la convivencia prematrimonial y de los hogares unipersonales en España (aunque no así en los países del centro y norte de Europa), la edad al matrimonio constituye un indicador bastante ajustado de la emancipación de los hijos y esta edad no ha hecho, como en el resto de países de la UE, más que aumentar de año en año, de forma que en 2002 la edad media al matrimonio de los varones españoles se situaba ya en los 30,6 años y en las mujeres en los 29 .

Detrás de esta postposición sistemática de la emancipación de la familia de origen y la constitución de un hogar independiente se encuentran tanto razones de orden económico, como razones de orden social y cultural. Entre las razones de orden económico hay que citar ante todo la elevada tasa de desempleo juvenil y la dualización del mercado de trabajo que ha ido registrándose a partir de mediados de la década de los setenta y que ha afectado, sobre todo, a los miembros que se han ido incorporando al mercado de trabajo, esto es, a los jóvenes y a las mujeres. Las aspiraciones a mantener al menos los niveles de consumo y el status social logrado por los padres, junto con las exigencias derivadas de una cultura juvenil centrada en elevados niveles de consumo de bienes y servicios de ocio, a la que se añade un modelo cultural donde la formación de un hogar independiente, y tanto más la constitución de una familia propia, pasa por el acceso a la propiedad de una vivienda plenamente equipada, en un contexto, por otra parte, donde el sistema de protección social de las rentas depende no tanto del estado de necesidad como de la carrera de aseguramiento que se ha podido formar, todos estos factores han contribuido decisivamente a hacer cada vez más difícil la formación de un hogar independiente y la necesidad de acumular durante más tiempo el capital necesario para poder emanciparse con arreglo a los modelos socialmente establecidos. En el contexto actual de una limitada movilidad geográfica, esta acumulación se ha hecho posible gracias a la prolongación de la permanencia en el hogar de los padres, facilitada por el profundo proceso de democratización de las relaciones intergeneracionales en el seno de la familia nuclear al reducir el control ejercido por los padres sobre el comportamiento de los hijos y evitar los consecuentes conflictos intergeneracionales. Así, no deja de resultar sorprendente que a pesar de esta prolongación de la permanencia en el hogar, y a la luz de los cambios culturales arriba esbozados, las relaciones entre padres e hi- 


\section{Cambios en las relaciones familiares y en la solidaridad...}

jos sean valoradas masivamente como positivas por éstos. En este sentido, el cambio familiar registrado en España en dirección hacia la privatización de los proyectos de vida familiar y la pluralización (limitada) de los modos de vida, lejos de minar una de las formas tradicionales de la solidaridad familiar, la ha reforzado en tiempos de crisis al redefinirla sobre unas nuevas bases.

TABLA 14. Titularidad de la vivienda de los matrimonios en función del número de años desde el inicio de la unión

\begin{tabular}{|l|c|c|c|c|}
\hline & $\mathbf{0 - 2}$ años & $\mathbf{3 - 5}$ años & 6 o más años & TOTAL \\
\hline En propiedad & 58 & 62 & 84 & 82 \\
\hline Alquilado & 31 & 22 & 10 & 12 \\
\hline Cedido & 10 & 16 & 5 & 6 \\
\hline Total & 100 & 100 & 100 & 100 \\
\hline$(\mathrm{N})$ & $(163)$ & $(323)$ & $(4.769)$ & $(5.255)$ \\
\hline
\end{tabular}

Fuente: Elaboración propia sobre datos de INE, Panel de hogares, 1994, microdatos, submuestra cabezas de familia casados.

Los datos contenidos en la Tabla 14 son claramente ilustrativos del alcance y la importancia de esta "solidaridad residencial» de los padres hacia sus hijos, evidenciando así la relevancia que tiene la familia española como mecanismo de estabilización social en un contexto marcado por una extendida frustración profesional derivada de la prolongación del período formativo y las elevadas tasas de desempleo, así como ilustra el papel decisivo que cumple como plataforma de colocación de sus miembros en la estructura social. Más de la mitad de los recién casados dispone de una vivienda en propiedad y del resto uno de cada cuatro disfruta de una vivienda cedida gratuitamente, que si bien la encuesta del INE "Panel de hogares, 1994» no proporciona información sobre quién la ha cedido, es razonable suponer que mayormente procede de la familia. El equipamiento de las viviendas de los jóvenes matrimonios con televisión en color, video, microondas, lavavajillas y teléfono, así como la posesión de un vehículo propio no difiere, por otro lado, del equipamiento medio de los hogares de las personas casadas y, por tanto, como media del equipamiento del hogar de sus propios padres. Aunque hay lógicamente diferencias por clases sociales así como promoción social intergeneracional, estos datos ilustran que durante la prolongación de la permanencia en 
casa de los padres los hijos han podido no sólo consolidar su situación en el mercado de trabajo a fin de poder hacer frente a un elevado endeudamiento por la compra de la vivienda, sino acumular el capital necesario para equipar su vivienda con arreglo al nivel medio de vida. El hecho de que la suficiencia de los ingresos para hacer frente a los pagos sea la misma que las dificultades que tienen el conjunto de los hogares (como media) para llegar a finales de mes evidencia que el proceso de independización no se hace habitualmente bajo condiciones especialmente críticas, lo que demuestra aun más claramente la importancia de la capitalización financiera durante la prolongación de la permanencia de los jóvenes en el hogar de los padres.

La solidaridad familiar juega, por tanto, un papel muy destacado en la formación del nuevo hogar y, por tanto, en el inicio de la biografía familiar de los hijos de acuerdo con los criterios socialmente establecidos. Una cuestión diferente, no obstante, es si los actores son conscientes o no de la importancia de la solidaridad familiar. Los datos de los que disponemos no sugieren una conciencia de la importancia que ésta tiene. Así, la mitad de los entrevistados casados o emparejados consideraban en 1990 que la ayuda recibida de su familia era insuficiente (48\%) (Alberdi, Flaquer e Iglesias de Ussel, 1994). Pero el hecho de que los actores no sean plenamente conscientes de las características de sus relaciones familiares, a pesar de tener sus consecuencias en términos de la calidad de sus relaciones, no afecta, sin embargo, al funcionamiento real de la solidaridad familiar.

Pero además de la facilitación del acceso a un hogar independiente, hay una parte no despreciable de casos en los que los padres facilitan el inicio de la biografía familiar de sus hijos en su propio hogar, alojando en su propia vivienda al hijo con la familia (cónyuge y eventualmente hijos) que ha formado. Así, según la explotación de la Encuesta de Población Activa que ha realizado Miguel Requena (Garrido y Requena, 1996), en 1995 había 717.000 personas casadas que vivían como hijos (consanguíneos o políticos) en el hogar del cabeza de familia. Aunque el número de personas que viven en casa de los padres habiendo iniciado su propia biografía familiar ha disminuído en el tiempo (en un $26 \%$ respecto a 1976), a mediados de los noventa todavía representaban un 3,5\% de los hogares encabezados por varones casados. La desagregación por edades y su evolución en el tiempo sugiere que en la mayor parte de los casos se trata de situaciones transitorias, pues la mayor proporción de casados que viven como hijos en el hogar del cabeza de familia se da entre los menores de 30 años y los porcentajes disminuyen de cohorte en cohorte a medida que 
Cambios en las relaciones familiares y en la solidaridad...

pasa el tiempo. El análisis de la situación económica de estas personas sugiere que no se trata mayormente del modelo de familia troncal, en virtud de la cual los hijos permanecen en casa de los padres porque heredan la actividad económica (agrícola o de servicios) del padre, sino que responde en general a situaciones económicas precarias caracterizadas por tasas relativamente altas de desempleo o de condiciones laborales precarias derivadas de la ausencia de un trabajo fijo. Una parte importante de estos hogares responden, por tanto, a situaciones en las que se inicia la biografía familiar sin las condiciones económicas necesarias para mantener un hogar independiente y al amparo de la solidaridad probablemente forzada de los padres.

Otra circunstancia vital en la que se plantea la demanda de «la solidaridad residencial» entre la red de parentesco es el envejecimiento y la muerte de uno de los padres. La edad y la viudedad como tales han dejado de ser causa necesaria del reagrupamiento de las generaciones, tanto para las mujeres, como incluso crecientemente también para los varones. Mientras viven ambos padres se mantiene el principio de separación residencial de las generaciones, la proporción de mayores en pareja que viven en casa de sus hijos es muy baja (menos de un $2 \%$ de los mayores de 65 años en 1998) y suele corresponder a situaciones especiales de necesidad de cuidado de los mayores. La muerte de uno de los mayores no es en sí misma causa inmediata del acogimiento del mayor en casa de los hijos, ni para las mujeres, ni entre tanto tampoco para los hombres, aunque la proporción de viudos que viven solos es minoritaria (un $28 \%$ de los varones y un 37\% de las mujeres mayores de 64 años en 1993) (Fundación Encuentro, 2001). La razón de ello está en la extensión de la «solidaridad residencial» de las generaciones, pero no sólo derivada de la norma de acogimiento de los mayores en el hogar de los hijos, sino porque en una apreciable proporción de hogares de los mayores enviudados todavía viven hijos solteros. De hecho viven casi tantos mayores de 64 años viudos con hijos en su casa ( $29 \%$, de los que algo más de la mitad tienen algún hijo soltero) como viudos viven en la de sus hijos (31\%). El número de hogares formados por personas mayores que viven solas está creciendo, tal como pude verse en la tabla 15. En este sentido, puede afirmarse que el principio que rige la convivencia entre las generaciones es, en la afortunada expresión de Rosenmayr, el de «intimidad a distancia», no exento, sin embargo, de ambivalencias. 
TABLA 15. Evolución del número de hogares españoles, 1985 - 2000. En miles.

\begin{tabular}{|l|r|r|r|c|}
\hline \multicolumn{1}{|c|}{ Tipos de hogares } & \multicolumn{1}{c|}{$\mathbf{1 9 8 5}$} & \multicolumn{1}{c|}{$\mathbf{1 9 9 5}$} & \multicolumn{1}{c|}{$\mathbf{2 0 0 0}$} & Aumento 1985/00 \\
\hline Solo de menos de 65 años & 409,7 & 430,8 & 564,3 & \multicolumn{1}{c|}{37,7} \\
\hline Solo de más de 65 años & 496,8 & 870,4 & 991,9 & 99,7 \\
\hline Pareja sin niños & $1.582,0$ & $2.015,2$ & $2.353,4$ & 48,8 \\
\hline Pareja con 1 niño & 704,5 & 931,5 & 839,8 & 19,2 \\
\hline Pareja con 2 niño & $1.142,8$ & 939,2 & 979,2 & $-14,3$ \\
\hline Pareja con 3 o más niños & 562,9 & 203,6 & 130,2 & $-76,9$ \\
\hline Adulto con niño(s) & 81,3 & 81,9 & 88,1 & 8,4 \\
\hline Otro tipo de hogar & $5.490,7$ & $6.459,7$ & $6.730,1$ & 22,6 \\
\hline Total & $10.470,7$ & $11.933,7$ & $12.677,1$ & 21,1 \\
\hline
\end{tabular}

Fuente: INE, Indicadores sociales, Madrid, varios años.

\section{Ayudas recibidas de la red familiar}

La red familiar funciona como «capital relacional» de reserva que según las circunstancias y necesidades puede activarse para resolver los problemas a los que se tiene que hacer frente en el curso de la vida. El tipo de ayuda que se puede obtener de la red familiar es muy amplio, yendo desde el sentimiento de pertenencia a una comunidad que funciona sobre la base de valores adscriptivos y particularistas, esto es, donde lo que cuenta es quién se es y no lo que se vale, hasta prestaciones sin contrapartida directa en forma de dinero o servicios personales de ayuda de todo tipo, pasando por la herencia de medios de vida. Este carácter de activo de reserva que solamente opera bajo circunstancias especiales plantea cuestiones difíciles de resolver desde el punto de vista metodológico, particularmente cuando se quiere estudiar cómo va cambiando, por lo que sólo puede ser explorado de forma aproximada.

Si dejamos de lado el papel de la familia en la construcción de la identidad personal y centramos la atención en la prestación de servicios de ayuda personal (cuidado de niños, ayuda en el "papeleo", reparaciones, etc.) o financieros (préstamos, regalos en forma de dinero u apoyo financiero), en nueve de cada diez familias, según nuestra «Encuesta sobre relaciones familiares en la Comunidad de Madrid», se ha recibido alguna ayuda de estas características en alguna ocasión de algún miembro de la red familiar y en dos de cada tres de las que no han recibido ayuda se acudiría, no obstante, a un familiar si en caso de enfermedad se necesi- 
tara la ayuda de alguien fuera del núcleo familiar para prestar cuidados, hacer camas, etc. De hecho, un $86 \%$ de los entrevistados acudiría a un familiar antes que a amigos, vecinos u otras personas si necesitara ayuda no médica en caso de enfermedad. Por lo que se refiere a apoyos de carácter menos concreto y más inmaterial, la red familiar también opera, como hemos visto más arriba, como compañía en la utilización del tiempo libre y de ocio, como medio para tener contactos sociales recurrentes y como interlocutores con los que expresar las preocupaciones, tristezas o alegrías vitales. La red familiar más próxima no es así sólo una especie de "seguridad social doméstica», sino también lugar de sociabilidad primaria.

Las circunstancias bajo las cuales se recibe ayuda son muy variadas, dependiendo de multitud de factores. Estas ayudas tampoco tienen necesariamente un carácter recurrente o continuo, sino que están adaptadas a las necesidades y posibilidades de cada momento tanto del donante como del receptor, por ello para analizar el alcance de las mismas no se preguntó en la encuesta por tipos de ayuda recibidas por el entrevistado en el año en el que se hizo la entrevista, sino en algún momento de su vida, salvo en lo que se refiere a ayuda en las tareas domésticas y en sus relaciones con las instituciones (Hacienda, Seguridad Social o bancos), en las que por razones obvias se preguntó sólo por el momento en el que se realizó la entrevista.

Las ayudas más frecuentes que se reciben son ayudas en el cuidado y atención de los niños, sobre todo cuando estos son (o eran) pequeños, antes de ir al colegio. Uno de cada dos entrevistados con hijos ha recibido ayuda de familiares en esta fase del ciclo familiar, siendo esta ayuda en la mitad de los casos (42\%) diaria, mientras que en los demás tenía un carácter más ocasional. Las ayudas en el cuidado y atención de niños escolares es algo más infrecuente (39\%), pero aún así, está también muy extendida y se da mayormente (67\%) más de forma ocasional para resolver necesidades puntuales (en vacaciones, en casos de enfermedad, para que los padres puedan salir de ocio sin los hijos, etc.) que de forma diaria. Esta ayuda ha sido más frecuente para los cónyuges más jóvenes que para los más mayores y en los casos en los que la mujer trabaja fuera de casa, pero también entre los demás colectivos. Las ayudas recibidas en este ámbito lejos de erosionarse, por tanto, parecen haberse intensificado entre las familias más jóvenes.

El segundo tipo de ayudas más frecuentemente recibidas es el hospedaje en el hogar de algún familiar. La mitad de los entrevistados (46\%) ha pasado un fin de semana o unos días de descanso en casa de algún fa- 
miliar durante el útimo año, normalmente en casa de los padres y suegros o de los hijos, aunque también con cierta frecuencia en casa de hermanos. Esta elevada frecuencia de hospedaje guarda relación no sólo con la elevada frecuencia de contacto entre los miembros de la red familiar próxima, sino también con la extendida utilización del tiempo libre y de ocio en el marco familiar, que hace que sea frecuente que todas o parte de las vacaciones se pasen también en compañía de familiares (un $71 \%$ de todos los encuestados ha pasado parte de sus vacaciones con algún familiar en los últimos 3 años).

TABLA 16. Ayudas recibidas de familiares según la edad y el sexo.

Porcentaje que declaran haber recibido...

\begin{tabular}{|l|c|c|c|c|c|}
\hline & \multirow{2}{*}{ Total } & \multicolumn{2}{|c|}{ Edad } & \multicolumn{2}{c|}{ Sexo } \\
\cline { 3 - 6 } & & $\mathbf{1 8 - 4 4}$ años & $\mathbf{4 5 - 6 5}$ años & Mujer & Hombre \\
\hline Ayuda en dinero para vivir & 8 & 10 & 5 & 7 & 8 \\
\hline Dinero prestado (1) & 35 & 41 & 29 & 37 & 32 \\
\hline Regalo en dinero(2) & 18 & 22 & 15 & 19 & 17 \\
\hline Disfrute temporal de bienes (3) & 26 & 33 & 18 & 24 & 29 \\
\hline $\begin{array}{l}\text { Herencia de un negocio/trabajo para } \\
\text { fam. }\end{array}$ & 2 & 3 & 1 & 2 & 3 \\
\hline Mediación para encontrar trabajo & 16 & 22 & 10 & 14 & 19 \\
\hline Ayuda en tareas domésticas & 17 & 31 & 42 & 43 & 26 \\
\hline Ayuda en "papeleo" & 15 & 14 & 16 & 17 & 11 \\
\hline $\begin{array}{l}\text { Ayuda en mantenimiento y } \\
\text { reparaciones }\end{array}$ & 28 & 29 & 27 & 27 & 30 \\
\hline En el cuidado de niños preescolares & 51 & 67 & 40 & 52 & 47 \\
\hline En el cuidado de niños escolares & 39 & 49 & 32 & 40 & 36 \\
\hline Hospedaje en casa de familiares & 46 & 49 & 42 & 46 & 46 \\
\hline
\end{tabular}

1 Cantidad de dinero importante prestada para sufragar obras, compra de una casa o un coche o para un negocio. Porcetaje sobre el total que han pedido prestado dinero para la adquisición de este tipo bienes.

2 Regalo en forma de dinero o herencia anticipada para sufragar gastos como en la columna anterior.

${ }^{3}$ Bienes como un coche, apartamento de vacaciones, vivienda y similares cedidos durante un tiempo y sin pago a cambio.

Fuente: G. Meil «Encuesta sobre relaciones familiares en la Comunidad de Madrid».

El tercer tipo de ayudas frecuentes tienen que ver con la situación financiera de las familias y más concretamente con el flujo de dinero o de bienes dentro de la red familiar. En principio las ayudas en dinero para vivir son infrecuentes y están limitadas a situaciones excepcionales, pues el principio que rige la dinámica de los hogares es su autonomía finan- 
Cambios en las relaciones familiares y en la solidaridad...

ciera. Entre nuestros entrevistados, sólo un 8\% recibía ayuda en forma de dinero para sufragar los gastos de la vida ordinaria, una proporción muy similar a la obtenida también en otras encuestas (en el Panel de Hogares, 1994 del INE, por ejemplo, donde sólo en un 10\% de los hogares reciben ingresos de otros hogares). Mucho más frecuente, por el contrario, es el regalo puntual de una cantidad de dinero importante, que afirman haber recibido uno de cada cinco entrevistados (18\%) para financiar bien la adquisición de una vivienda (44\% de los casos), bien para hacer frente a obras de mejora de la misma (14\%), para la adquisición de un coche $(12 \%)$ o para la adquisición de otros bienes. Pero más que la transmisión de propiedad en vida o de dinero para su adquisición, lo más frecuente es el préstamo de bienes o de dinero. Uno de cada tres encuestados que afirma haber necesitado tomar prestado dinero para un desembolso importante, ha acudido a miembros de la red familiar, ya sea de forma transitoria hasta conseguir un préstamo bancario o de forma sustitutiva al préstamo de una entidad financiera, estando estos préstamos fundamentalmente destinados a la adquisición de una vivienda (72\%), aunque también ha sido relativamente frecuente para la compra de un coche $(20 \%)$. Por otra parte, uno de cada cuatro entrevistados ha recibido prestado para su uso temporal bien un coche ( $51 \%$ de los casos), bien un apartamento o casa de vacaciones (36\%) o una vivienda (28\%). En conjunto, tomando en consideración todas estas ayudas, uno de cada dos entrevistados ha recibido en alguna ocasión bien sea dinero prestado o regalado o algún bien en usufructo.

El cuarto ámbito en las que se recibe ayuda se refieren al funcionamiento ordinario del hogar, tales como el resolver tareas domésticas o el «papeleo», aunque en estos casos la ayuda que recibe el entrevistado o su cónyuge procede fundamentalmente de hijos que conviven en el hogar. Si se excluyen estas ayudas, la implicación de miembros fuera del hogar es relativamente limitada, centrándose en mayor medida en la ayuda en el acondicionamiento o mejora de la casa, en el cuidado del coche o en otras tareas similares, ayuda de la que se ha beneficiado uno de cada cuatro encuestados.

Por último, la familia como capital relacional para encontrar un empleo ha sido reiteradamente señalada, pero tan importante como la familia son también otros conocidos, ya sean éstos amigos o simples conocidos. Entre los entrevistados de este estudio, no obstante, fueron mucho más los que consiguieron un empleo gracias a un familiar (16\%) que los que lo hicieron gracias a la intervención de no familiares $(9 \%)$ y en mayor medida los más jóvenes que los más mayores. 
El flujo de estas ayudas no procede de forma indiferenciada de todos los miembros de la red familiar, sino que, por el contrario, presenta pautas muy claramente estructuradas. Las principales características de esta estructura son:

1. En primer lugar, los familiares más alejados no aparecen como prestadores de ayuda, ni emocional, ni financiera, ni en servicios personales, salvo los tíos en algunos casos muy puntuales. Las ayudas proceden, por el contrario, casi exclusivamente del círculo familiar más próximo, esto es, de la familia nuclear de origen. En este sentido resulta especialmente llamativo que los abuelos no jueguen prácticamente ningún papel como fuente de solidaridad familiar para sus nietos ya adultos e independizados, centrándose su ayuda, sobre todo, en la fase en la que fueron niños. Así, aunque no están ausentes en las ayudas financieras, su importancia es menor incluso que la de los tíos.

2. Dentro del círculo de la familia nuclear de origen, la principal fuente de ayuda procede de los padres, con una diferencia abrumadora respecto a lo que se recibe de los hijos. Investigaciones llevadas a cabo en otros países (Attias-Donfut, 1995) han puesto de relieve que mientras las ayudas financieras procedían de los padres (varones), las ayudas recibidas en forma de servicios personales procedían fundamentalmente de las madres, pauta que en España se ha podido observar entre los viudos mayores de 65 años, pero no así entre los casados de dicha edad, probablemente debido, por un lado, a la importante diferencia de ingresos entre los viudos y las viudas y porque, por otro lado, entre los mayores casados la administración del dinero es conjunta y las relaciones con la madre suelen ser más estrechas que con el padre (Meil, 2000). En el caso que nos ocupa, aunque la ayuda recibida en forma de dinero, ya sea prestado o regalado, así como el usufructo de bienes tiende a recibirse con mayor frecuencia del padre que de la madre, las diferencias no son significativas, no sólo por el limitado alcance de las mismas, sino sobre todo porque dos de cada tres entrevistados han identificado conjuntamente a su padre y a su madre como los prestadores de la ayuda.

3. Las ayudas en servicios personales, por el contrario, sí están fuertemente diferenciadas según el sexo, de forma que el cuidado de niños o la ayuda en las tareas domésticas procede fundamentalmente (aunque no exclusivamente) de la madre, mientras que las ayudas recibidas para el papeleo o para reparaciones domésticas o el mantenimiento del coche proceden fundamentalmente (aunque tampoco exclusivamente) del padre. El hecho de que las diferen- 
cias sean apreciables pero no extremas es un signo, creemos, de que los tradicionales roles de género familiares se encuentran sujetos a un proceso de (lenta) redefinición, como se evidencia también en el papel diferencial como mediadores a la hora de obtener un empleo, en cuyo caso el menor papel de la madre es atribuible a su menor grado de integración en el mercado de trabajo.

4. Comparativamente con los suegros, los padres aparecen con mucha más frecuencia citados que éstos como fuente de ayuda en cualesquiera de la dimensiones consideradas. La razón de esta diferencia no deriva sólo de la mayor frecuencia de mujeres entre los entrevistados, pues tanto varones como mujeres citan a sus padres mucho más que a sus suegros como fuente de la ayuda (salvo en el cuidado de niños, donde los varones citan con similar frecuencia a suegras y a madres), sino también de las percepciones diferenciales de la realidad que lleva a destacar más lo más cercano sobre lo más distante. No obstante, de esta pauta cabe deducir que las ayudas no proceden solamente de la familia de la mujer, frente a la del marido, sino que los núcleos conyugales reciben, en conjunto, ayudas por ambas vías, estando más orientadas en una dirección u otra según sean las circunstancias.

5. Frente a los padres, los hijos, por el contrario, apenas aparcen como fuentes de ayuda en las dimensiones que estamos considerando, salvo en lo que se refiere a la ayuda doméstica y a resolver «el papeleo", que desempeñan mayormente cuando conviven con los padres. Las «contrapartidas» que los hijos dan a los padres se ubican, sobre todo, en el plano relacional de la utilización del tiempo libre y de la sociabilidad comunitaria, siendo además en algunos casos (sobre todo en las relaciones madre-hija) los interlocutores en quienes «descargar» los sentimientos y preocupaciones más íntimos. De una forma gráfica, por tanto, puede decirse que la ayuda en dinero o servicios funciona con arreglo al modelo de "cascada".

6. Los hermanos y sobre todo las hermanas, por el contrario, tienen o han tenido un papel mucho más activo que los hijos, estando especialmente presentes en las ayudas financieras y préstamo de bienes para su disfrute temporal, en el cuidado de niños, en el hospedaje, como mediadores para encontrar un empleo y, sobre todo, como confidentes. Tras los padres, las hermanas y en menor medida los hermanos son los principales recursos con los que cuentan los núcleos conyugales cuando necesitan ayuda, sobre todo en la fase del ciclo familiar en que los hijos son pequeños, mucho más que los amigos. No obstante, la extensión de estas ayudas es limitada, pues sólo uno de cada tres entrevistados ha recibido algún tipo de las ayudas consideradas de sus hermanos. 


\section{Ayudas prestadas a otros miembros de la red familiar}

Los núcleos conyugales no sólo son receptores de ayuda, sino que también prestan apoyo y ayuda a los miembros de la red familiar. De hecho, nueve de cada diez entrevistados han prestado algún tipo de las ayudas consideradas, sin que existan diferencias significativas en razón del sexo, a lo que hay que añadir que tres de cada cuatro mujeres entrevistadas (70\%) y la mitad de los varones (52\%) actúan como interlocutores privilegiados de los aspectos más íntimos e importantes de otros miembros de la red familiar. Lo más frecuente es haber prestado una (24\%) o dos ayudas (20\%), siendo los casos en los que se prestan cuatro o más relativamente infrecuentes (31\%). Comparativamente con las ayudas recibidas, la proporción de los que han proporcionado algún tipo de ayuda y los que la han recibido es prácticamente igual, pero consideradas una a una las distintas dimensiones se declara con más frecuencia recibir ayuda de miembros de la red que prestarla a otros miembros. Estas diferencias pueden deberse al desequilibrio intergeneracional en el flujo de las ayudas, esto es, a la mayor propensión de los padres a ayudar a los hijos particularmente en el proceso de emancipación de su hogar y cuando tienen hijos pequeños, tal como sugiere la desagregación de los datos de ayuda recibida en función de la edad y como también se ha puesto de relieve en otros países. El limitado peso dentro de la encuesta de los entrevistados con hijos emancipados (23\%), consecuencia de limitar el universo muestral a hogares cuyo cabeza o cónyuge tuviese entre 18 y 65 años, estaría en el origen de estas diferencias. Ahora bien, si se tiene en cuenta que es más habitual afirmar que se han prestado ayudas que reconocer que se han recibido, pues la memoria opera de forma selectiva, la interpretación más plausible es que los entrevistados tiendan a subestimar el alcance de los intercambios de ayuda dentro de la red y a expresar sólo las ayudas de mayor importancia, ya sea por el volumen de recursos implicados o por el tiempo y energía invertidas en las mismas.

Las ayudas que con mayor frecuencia se han prestado se refieren también al cuidado de niños, tanto en edad preescolar como en edad escolar, así como en las tareas domésticas. Entre una de cada tres y una de cada dos miujeres y alrededor de uno de cada seis varones han ayudado o ayudan a otros familiares en estas tareas. Aunque la ayuda en el cuidado de los niños es más frecuente entre las entrevistadas que son abuelas (57\% a niños preescolares y $47 \%$ a niños escolares) y en menor medida entre los abuelos ( 38 y $32 \%$ respectivamente), este tipo de ayudas no se prestan solamente en esta fase del ciclo familiar sino a lo largo de todo el ciclo de vida. En el caso de los abuelos, los beneficiarios del cuidado son los nietos, mientras que en los demás casos se trata de los sobrinos, fundamental- 


\section{Cambios en las relaciones familiares y en la solidaridad...}

mente los hijos de los hermanos carnales y mayormente entre hermanas. El cuidado de los sobrinos es, como es fácilmente imaginable, de carácter ocasional y esporádico, pero también el de los nietos. Así dos de cada tres abuelos (65\% de las abuelas y $73 \%$ de los abuelos) afirman haber cuidado de niños preescolares de forma ocasional, en casos de enfermedad, para salir, etc., y sólo uno de cada tres entrevistados abuelos afirman haberlo hecho de forma continua, cuando los padres trabajaban. Las proporciones para el cuidado de niños escolares son similares (67 y $83 \%$ respectivamente). Estos datos junto con los ya discutidos sobre ayudas recibidas y con los que se obtienen de otras encuestas evidencian que los abuelos son un importante recurso para la conciliación de vida familiar y vida laboral de sus hijos, pero sólo en un limitado número de casos son el único o principal recurso disponible y la figura de la «nueva abuela» implicada en una «segunda maternidad» con el cuidado y atención de sus nietos, aunque se dé con cierta frecuencia, no es la pauta social dominante.

TABLA 17. Ayudas prestadas a familiares según la edad y el sexo Porcentaje que declaran haber proporcionado..

\begin{tabular}{|c|c|c|c|c|c|}
\hline & \multirow{2}{*}{ Total } & \multicolumn{2}{|c|}{ Edad } & \multicolumn{2}{|c|}{ Sexo } \\
\hline & & $18-44$ años & $45-65$ años & Mujer & Hombre \\
\hline Ayuda en dinero para vivir & 10 & 8 & 12 & 9 & 12 \\
\hline Dinero prestado (1) & 24 & 21 & 26 & 25 & 20 \\
\hline Regalo en dinero (2) & 8 & 7 & 9 & 9 & 7 \\
\hline Disfrute temporal de bienes (3) & 22 & 20 & 23 & 18 & 28 \\
\hline $\begin{array}{l}\text { Herencia de un negocio/trabajo para } \\
\text { fam. }\end{array}$ & 21 & 1 & 3 & 1 & 4 \\
\hline Mediación para encontrar trabajo & 18 & 18 & 18 & 16 & 22 \\
\hline Ayuda en tareas domésticas & 26 & 26 & 27 & 32 & 16 \\
\hline Ayuda en "papeleo" & 12 & 14 & 10 & 11 & 15 \\
\hline $\begin{array}{l}\text { Ayuda en mantenimiento y } \\
\text { reparaciones }\end{array}$ & 20 & 23 & 17 & 17 & 26 \\
\hline En el cuidado de niños preescolares & 25 & 24 & 26 & 30 & 16 \\
\hline En el cuidado de niños escolares & 21 & 20 & 22 & 25 & 12 \\
\hline Cuidado de familiares incapacitados & 11 & 11 & 11 & 12 & 5 \\
\hline
\end{tabular}

${ }^{1}$ Cantidad de dinero importante prestada para sufragar obras, compra de una casa o un coche 0 para un negocio. Porcetaje sobre el total que han pedido prestado dinero para la adquisición de este tipo bienes

${ }^{2}$ Regalo en forma de dinero o herencia anticipada para sufragar gastos como en la columna anterior

${ }^{3}$ Bienes como un coche, apartamento de vacaciones, vivienda y similares cedidos durante un tiempo y sin pago a cambio

Fuente: G. Meil «Encuesta sobre relaciones familiares en la Comunidad de Madrid». 
La ayuda en las tareas domésticas y en la compra también se encuentra bastante extendida, siendo mucho más frecuente en las mujeres que en los varones, aunque entre éstos no es tampoco testimonial: una de cada tres mujeres frente a uno de cada seis varones entrevistados, sin diferencias significativas según la edad, ayuda a algún otro miembro de la red familiar con el que no convive ya sea de forma regular o de vez en cuando en el momento de la entrevista. Los principales beneficiarios de estas ayudas son los padres, aunque también cabe encontrar este tipo de ayuda a los hijos emancipados y a hermanas, discurriendo en este caso la ayuda casi exclusivamente por vía femenina: una mujer ayuda a sus padres, a una hermana o a una hija. La situación inversa se da, por el contrario, en las ayudas para el mantenimiento y obras en vivienda y coches, aunque en este caso el flujo de la ayuda no discurre sólo a través de la línea masculina, pues hermanas e hijas son en igual medida beneficiarias de estas ayudas como lo son los hermanos y los hijos.

La ayuda financiera para vivir es poco frecuente y cuando se da suele ser a hijos mucho más que a padres, discurriendo fundamental aunque no exclusivamente por línea vertical, como sucedía también cuando se analizaron desde el punto de vista de las ayudas recibidas. Sólo un 3\% de los encuestados con algun progenitor vivo ayudaba económicamente con dinero a sus padres y los que lo hacían no lo hacían de forma regular, sino ocasionalmente, según las necesidades, por lo que los medios de vida de la generación de los mayores procede exclusivamente de las pensiones y de los ahorros acumulados. Sólo en los hogares donde conviven las generaciones existe cierto grado de economía común. Los préstamos de dinero y la cesión temporal de bienes son, por el contrario, mucho más frecuentes y se inscriben no sólo en las relaciones verticales, sino que incluyen igualmente a colaterales. Así, los hermanos aparecen con más frecuencia citados como beneficiarios de préstamos de dinero y de disfrute temporal de bienes que los hijos y que los padres. La escasa importancia relativa de los hijos como beneficiarios de los préstamos se debe a los efectos del ciclo familiar, pues uno de cada tres padres que tiene algún hijo emancipado ha prestado dinero. Por otro lado, los bienes más frecuentemente cedidos son en dos de cada tres casos coches y en mucha menor medida viviendas (uno de cada tres). Los regalos de dinero para contribuir a sufragar la compra de una vivienda, un coche $\mathrm{u}$ otros gastos importantes son también poco frecuentes y tienen como destinatarios preferentes a los hijos, aunque padres y hermanos aparecen también citados con cierta frecuencia, estando estos regalos destinados en los pocos casos en que se producen a financiar fundamentalmente la adquisición de coches y viviendas. 
Cambios en las relaciones familiares y en la solidaridad...

Al igual que sucedía con las ayudas recibidas, las ayudas prestadas para encontrar un empleo están relativamente extendidas, no beneficiando además sólo a la familia, sino también, e incluso en mayor medida, a amigos y conocidos. Entre los familiares, los principales beneficiarios son los colaterales, más los consanguíneos, pero también políticos, y en menor medida los hijos. Dar en herencia un negocio o dar trabajo a un familiar es muy poco frecuente e implica fundamentalmente a hijos.

En conjunto y por lo que se refiere al flujo de las ayudas prestadas por el entrevistado puede observarse también una clara estructura caracterizada por los siguientes rasgos:

1. Como en el caso de las ayudas recibidas, las ayudas prestadas a otras personas lo son fundamentalmente a familiares, aunque tampoco exclusivamente a éstos.

2. Los amigos, aunque no son los principales protagonistas de la «economía solidaria» sí aparecen con una frecuencia no despreciable como destinatarios de ayuda para encontrar un empleo, como beneficiarios del usufructo temporal de bienes duraderos, reciben dinero prestado y ayudas ocasionales en el cuidado de niños o en las reparaciones domésticas. Así, algo menos de uno de cada tres entrevistados ha ayudado a algún amigo de forma desinteresada en alguna de las dimensiones consideradas, siendo más frecuente entre los varones que entre las mujeres ( 36 y $24 \%$ respectivamente). Esta mayor propensión de los varones a invertir en las redes de amistad que las mujeres se encuentra también en la dimensión del intercambio de preocupaciones y experiencias íntimas con otras personas, mucho menos frecuente entre los varones, pero que cuando tiene lugar tiene como destinatario a los amigos antes que a los familiares (uno de cada dos varones (45\%) elige a amigos más que a familiares como confidentes frente a una de cada tres mujeres $(36 \%))$.

3. Por lo que se refiere al flujo de ayudas dentro de la red familiar, las ayudas prestadas se centran, como las recibidas, casi exclusivamente dentro del círculo de la familia nuclear de origen, quedando excluidos los familiares más alejados, no sólo tíos, primos o políticos, sino también los abuelos se encuentran fuera del círculo más estrecho de la «economía solidaria familiar». Con ello no queremos decir que los mayores necesitados de cuidado personal no sean atendidos casi exclusivamente por familiares, como está ampliamente demostrado, sino que los abuelos no son cuidados en caso de necesidad por los nietos, sino por sus hijas -las madres de 


\section{Gerardo Meil Landwerlin}

los entrevistados- (sólo un 5\% de los entrevistados que afirman cuidar de un familiar necesitado de ayuda para la realización de las tareas cotidianas lo hace a sus abuelos). Las ayudas se dan (como se recibían también), por tanto, entre generaciones contiguas, pero no entre generaciones discontinuas.

4. De igual forma y como sucedía también con las ayudas recibidas, la familia política apenas si aparece como destinataria de las ayudas prestadas por el entrevistado, como tampoco aparecen como interlocutores privilegiados para la comunicación de los aspectos más íntimos de los miembros de la red. De hecho, en muchas de las dimensiones aparecen menos veces citados que los amigos. Las razones de este desequilibrio entre consanguíneos y políticos no se debe, creemos, a una lateralización extrema del flujo de intercambios entre los núcleos conyugales, sino que deriva del hecho de que la unidad de análisis no es la unidad conyugal, sino sólo uno de lo cónyuges.

5. Por lo que se refiere a los familiares más próximos, y a diferencia de lo que sucedía con la ayudas recibidas, los destinatarios de las ayudas de los encuestados se reparten más homogéneamente entre los colaterales, ascendientes y descendientes, no existiendo un desequilibrio tan marcado a favor de las relaciones padres-hijos. De hecho, los padres sí aparecen con cierta frecuencia como receptores de las ayudas de sus hijos, sobre todo, en lo que se refiere a servicios personales, ya sea en el ámbito de las tareas domésticas, en el "papeleo", en el mantenimiento o mejoras de la vivienda o el coche o en el cuidado personal cuando ya no pueden realizar sin ayuda las tareas cotidianas de la vida. Los hijos aparecen como beneficiarios, sobre todo, de ayudas financieras, usufructo temporal de bienes y ayuda en el cuidado de niños, particularmente cuando se han emancipado, mientras que los hermanos aparecen también como beneficiarios ocasionales de este mismo tipo de ayuda o de ayudas en la mejora y mantenimiento de la vivienda o el coche. También en este caso cabe encontrar una diferencia importante según el sexo, como ya hemos apuntado, de forma que las hermanas se prestan ayuda entre ellas en el cuidado de niños y en algún caso también en tareas domésticas o la compra, mientras que las ayudas en mejora y mantenimiento de viviendas o coches está indiferenciada, como también está indiferenciada según el sexo la circulación de dinero ya sea prestado o regalado. 
Cambios en las relaciones familiares y en la solidaridad...

\section{Cambio familiar y solidaridad familiar}

A partir del análisis pormenorizado realizado en los apartados anteriores puede observarse que la red familiar continua ocupando un lugar privilegiado en el sistema de relaciones sociales de las personas, constituyendo el principal contexto de sociabilidad en el tiempo libre y de ocio a partir del momento en el que se inicia la biografía familiar y ello independientemente de la clase social de pertenencia. Las variables que explican la frecuencia de contactos con los miembros de la red próxima de parentesco se centran fundamentalmente en el sexo del entrevistado y la distancia geográfica entre los lugares de residencia de padres, hijos y hermanos. Las variables que miden el cambio familiar tales como institucionalización o no del vínculo conyugal, ideología de rol de género, trabajo extradoméstico de ambos cónyuges y pauta de división del trabajo doméstico no influyen, por el contrario, en absoluto en estas pautas de relación. Los entrevistados, aunque vivan en una pareja de hecho, con modelos de rol igualitarios, trabajando ambos y dividiéndose las tareas domésticas de forma no tradicional, no ven con menor frecuencia a sus padres o hermanos, controlados los efectos de la distancia y del sexo, que un matrimonio organizado con arreglo al modelo tradicional de roles de género. Así, 8 de cada diez entrevistados que viven en pareja de hecho y a una distancia de menos de 15 minutos a pie de sus padres les ven más de una vez a la semana, proporción idéntica a la de los casados. Si el tipo de vínculo legal que une a los cónyuges no afecta a la frecuencia de contacto con los padres, como tampoco afecta a la calidad de esta relación ${ }^{4}$, tampoco tiene por qué afectar a la frecuencia de contacto con los hermanos, como, de hecho, tampoco afecta: tres de cada cuatro entrevistados casados y algo más de los que viven en pareja que tienen su residencia a menos de 15 minutos a pie de un hermano/a ven a éste/a con una frecuencia de al menos una vez por semana. A ello se une el hecho además, como vimos, que el cambio familiar en sus distintas manifestaciones no se traduce tampoco en un mayor distanciamiento geográfico de las generaciones y de la red de parentesco.

El proceso de privatización creciente de los proyectos de vida familiar que ha conocido la sociedad española y que se ha traducido en una pérdida del tradicional control social ejercido por el entorno social y activamente impulsado por la familia en favor de una mayor libertad de conformación de los proyectos de vida individuales no ha comportado así un debilitamiento de la sociabilidad familiar dentro del círculo más próximo integrado por los miembros del núcleo familiar de origen. El hecho de que 


\section{Gerardo Meil Landwerlin}

las parejas de hecho vean con tanta o más frecuencia a amigos que a familiares no se debe a una supuesta ruptura con la familia, de la que no hay signos, sino a las circunstancias propias del ciclo de vida familiar y que también se dan entre los matrimonios sin hijos. La ausencia de hijos, mucho más frecuente en las uniones de hecho, se traduce en una mayor disponibilidad de tiempo libre y en un contacto más frecuente con las amistades. Cuando hay niños y los abuelos no viven lejos, el tiempo de ocio, trabajen o no ambos progenitores, tiende a centrarse en la visita a los abuelos más que en la salida con los amigos y, en cualquier caso, ésta suele pasar por el cuidado de los niños por los abuelos. El proceso de individualización, o de liberación de las regulaciones tradicionales, según la conceptualización de Ulrich Beck, aunque haya podido debilitar profundamente la institución matrimonial no ha comportado una pérdida de funcionalidad del carácter expresivo de la red de parentesco próxima o nuclear (en el sentido del núcleo familiar de procedencia).

Las relaciones con la red de parentesco más alejada, por otro lado, han ido debilitándose y espaciándose en el tiempo con el proceso de urbanización e industrialización, como lo evidencia el hecho de su mayor intensidad en las zonas menos urbanizadas (del Campo y Navarro, 1985; de Pablo, 1976). El proceso de privatización creciente de los proyectos de vida familiar apenas sí ha influido en este proceso, de forma que hoy como en el pasado más reciente el contacto con primos o tíos más allá de las celebraciones y rituales familiares depende más de criterios afectivos que estatutarios. Si se ve a un primo con cierta frecuencia, es más por su condición de amigo que por el vínculo familiar.

Si la dimensión expresiva de las relaciones familiares no se ha visto sustancialmente alterada por la postmodernización de la vida familiar, sus efectos sobre la dimensión instrumental son, por el contrario, más ambiguos. Por un lado y como hemos visto, hay múltiples indicadores que apuntan hacia su fortalecimiento, pero también hay otros que lo hacen hacia su debilitamiento o, quizá habría que decir más bien, hacia una redefinición de la solidaridad familiar como «solidaridad de emergencia». Así, entre los primeros hay que citar la prolongación durante cada vez más tiempo de los jóvenes en casa de sus padres y el apoyo económico que en dicho contexto se les brinda, ya sea, en expresión de Pitrou, bajo la forma de "solidaridad de subsistencia" o bien bajo la forma de "solidaridad de promoción». En el primer caso, se trata fundamentalmente de hospedaje, alimentación y cuidado personal hasta adquirir independencia económica suficiente para poder iniciar un proyecto de vida propio en un hogar independiente, sirviendo la solidaridad intergeneracional para ha- 
Cambios en las relaciones familiares y en la solidaridad...

cer frente al masivo desempleo juvenil y a la precarización de los nuevos contratos laborales. En el segundo caso se trata, además de garantizar la subsistencia, de facilitar el acceso a una formación de calidad que permita la consolidación y promoción profesional y el acceso a la propiedad de la vivienda antes de iniciar el ciclo de vida familiar. La crisis del empleo iniciada en la segunda mitad de los setenta ha forzado así ambos tipos de solidaridad entre las generaciones en el seno de los núcleos familiares, amortiguando con ello los efectos del extendido desempleo juvenil, allanando el camino a la reforma del mercado de trabajo y la reestructuración económica, al tiempo que facilitaba a los jóvenes unos niveles de consumo desconocidos para las generaciones precedentes, tanto en lo que se refiere al consumo juvenil propiamente dicho, como en lo que se refiere al acceso a la propiedad de la vivienda ( $y$ su adecuado equipamiento) en la que iniciar un proyecto de vida independiente de la familia de origen. Así, las ayudas en dinero, con arreglo fundamentalmente al principio del préstamo, como se ha visto, lejos de debilitarse se han incrementado entre las generaciones más jóvenes: mientras que entre los menores de 30 años que han solicitado prestado dinero para la adquisición de una vivienda un $41 \%$ lo ha pedido no sólo al banco sino también a familiares, entre los mayores de 50 años dicho porcentaje se reduce al $27 \%$. Si establecemos un corte de edad convencional a los 45 años, los menores de dicha edad (emancipados ya) declaran en mayor proporción que los mayores de dicho límite (hasta los 65 años) haber recibido dinero prestado, regalado, ayuda en forma de dinero para vivir así como bienes cedidos temporalmente para su disfrute. Inversamente, los mayores de 45 años declaran en mayor medida que los menores de dicha edad haber prestado o regalado a otros familiares dinero o bienes. En algunos casos estas diferencias no son significativas, mientras que en otras sí, pero en cualquier caso evidencian que, lejos de debilitarse, la solidaridad material en esta dimensión no ha dejado de perder su carácter instrumental, incluso entre las familias postmodernas.

Por lo que se refiere a la prestación de servicios de ayuda que implican dedicación y tiempo tampoco cabe encontrar signos claros y contundentes de un debilitamiento en la disposición a la ayuda en los casos de necesidad. Por el contrario, la solidaridad intergeneracional parece haberse reforzado. Así, las proporciones de los que prestan ayuda a otros familiares con los que no conviven en la compra o en la realización de las tareas domésticas, en reparaciones y mantenimiento, en la resolución de problemas burocráticos o en el cuidado de niños no varía sustancialmente con la edad ni con los indicadores más claros del cambio familiar 
(vínculo conyugal, incorporación de la mujer al mercado de trabajo e ideología de rol). Si se consideran las ayudas recibidas por las generaciones más jóvenes, éstas tienden a afirmar en mayor medida el haber recibido ayuda que las más mayores, sobre todo, en la crucial dimensión del cuidado de los niños. La excepción parecen serlo las ayudas en las tareas domésticas, pero las respuestas dadas por los entrevistados recogen no sólo las ayudas de miembros de fuera del hogar, sino también la de los hijos que conviven con sus padres, por lo que la menor ayuda en esta dimensión entre las familias más jóvenes no deriva de un debilitamiento de la solidaridad familiar en esta dimensión, sino de los efectos del ciclo familiar. Por lo que se refiere al cuidado de niños, entre las familias más jóvenes las ayudas recibidas ya sea para el cuidado de niños escolares o preescolares, lejos de disminuir parecen haber aumentado, beneficiando, como se ha señalado más arriba, en mayor medida a las familias en las que ambos padres trabajan que a las familias con una división de roles de tipo tradicional. Estas ayudas, no obstante, tienden a tener un carácter «limitado", ya sea porque el cuidado es ocasional y no continuado cuando los padres trabajan, o por comenzar la escolarización a edades muy tempranas (a los 3 años). El hecho de que estas ayudas sean calificadas como «limitadas» no implica en absoluto que sean irrelevantes, antes bien al contrario, contribuyen decisivamente a facilitar la conciliación de vida familiar y vida laboral o a organizar mejor la vida cotidiana, pero sólo en un limitado número de casos, como se ha argumentado más arriba, constituye esta ayuda un esfuerzo temporal equivalente a una jornada laboral. En este sentido, por tanto, la gran mayoría de los servicios de ayuda mutua que fluyen a través de «la economía solidaria familiar», son ayudas limitadas en cuanto al tiempo y/o esfuerzo que requieren para prestarlas, no suponiendo una carga equivalente a la asunción de una segunda jornada laboral. La disposición para prestar este tipo de servicios de ayuda a los familiares próximos no se ha erosionado así con el proceso de privatización registrado en las últimas décadas, ni ha comportado tampoco la exclusión de los flujos de ayuda puntuales a los familiares colaterales (hermanos y hermanas). No obstante, la disposición para asumir servicios de ayuda que impliquen una dedicación temporal prolongada en el tiempo y que requieran un elevado esfuerzo, de forma que constituyan una auténtica carga laboral, creemos que, aunque continúa jugando un importante papel dentro de las redes familiares en la actualidad, está sujeta a un proceso de redefinición. Esta redefinición supone que se pasa de una actitud en la que sólo se admite el cuidado familiar a dar cabida también a la intervención de cuidadores no familiares, sin que 
ello implique un desentendimiento por parte de los familiares. Expresado en otros términos, lo que el proceso de privatización ha empezado a cuestionar, creemos, no son las ayudas puntuales más o menos regulares a miembros de la familia, sino fundamentalmente la disposición de los abuelos a asumir el rol de padres cuando sus hijos trabajan (o la de éstos para delegar estas responsabilidades en sus padres) y la disposición (o capacidad) de los hijos (hijas fundamentalmente) a cuidar de sus mayores sin ayuda exterior cuando se han vuelto dependientes y necesitan de cuidado continuado.

Para fundamentar esta tesis discutiremos brevemente los datos sobre estos dos tipos de ayudas desde otra perspectiva. Por lo que se refiere al cuidado continuado de niños preescolares, la información que proporcionan las encuestadas con hijos de 3 o menos años indican que la ayuda diaria recibida de familiares (abuelos fundamentalmente) cuando los padres están trabajando está bastante extendida ( $42 \%$ de las mujeres que trabajan), aunque, por otro lado, sólo el $21 \%$ de las abuelas encuestadas declaran haber cuidado de sus nietos diariamente cuando los padres de éstos trabajaban. Estos datos comparados con los de las generaciones precedentes indican que las abuelas han contribuido decisivamente a facilitar la incorporación de las mujeres al mercado de trabajo y que la solidaridad intergeneracional se ha reforzado con la postmodernización de la familia, como hemos señalado anteriormente. Pero como en el caso de la botella medio llena y medio vacía, estos datos también puede leerse desde el punto de vista inverso: son mayoría quienes no acuden a la ayuda familiar para resolver el problema de la conciliación de la vida familiar y vida laboral. A falta de datos longitudinales consistentes, creemos que el modelo del cuidado de los niños preescolares antes de ir al colegio por parte de los abuelos está perdiendo vigencia en favor de un modelo de ayuda «de emergencia» que suponga un recurso adicional para las familias con hijos pequeños a la hora de conciliar ambas obligaciones, pero no el recurso fundamental. Se busca o presta la ayuda, pero cada vez más como complemento a otros servicios profesionales. Así, preguntados los encuestados si era preferible que un niño pequeño vaya a una guardería cuando ambos padres trabajan o es mejor que los cuiden los abuelos, varones y mujeres menores de 50 años se decantaban mayoritariamente a favor de la guardería (o una «chica», 66\%) y entre los mayores de dicha edad las opiniones estaban divididas (sólo un $52 \%$ se decantaba claramente a favor de los abuelos). En este sentido, la ampliación de la oferta de Escuelas infantiles ya sean públicas o privadas (aunque con preferencia por aquéllas), junto con la mejora de la capacidad económica de las familias, lleva no tanto 


\section{Gerardo Meil Landwerlin}

a prescindir de la red familiar y singularmente de los padres como fuente de ayuda en el cuidado de los niños, como a no sobrecargar su capacidad de ayuda y reducir así la dependencia exclusiva de la red familiar.

Esta misma erosión en el plano normativo cabe encontrarla también respecto al cuidado de los ancianos necesitados de ayuda, aunque las actitudes en este aspecto son ambiguas. La elevada sensibilidad de las respuestas a la redacción de las preguntas no hace sino reflejar el conflicto entre las normas de solidaridad familiar tradicionales y la tendencia hacia una concepción de ésta con un carácter más de ayuda y atención que de dedicación continuada, en la que las responsabilidades familiares se articulan con la colaboración de "ayudas» no familiares (servicios sociales, «chica», residencia, etc.). Así, la idea de que «lo mejor que uno puede hacer es ayudar a sus padres ancianos» es universalmente aceptada en la sociedad española, pero también está generalizada la idea de que «el cuidado de los padres ancianos no es un problema exclusivo de los hijos, sino que atañe igualmente a la sociedad y al Estado $»^{5}$. En nuestra encuesta una de cada dos mujeres y uno de cada tres varones ( 46 y $39 \%$ respectivamente) se mostraban de acuerdo con la proposición «en la vejez, cuando uno no puede valerse solo, si se puede conseguir la ayuda de los Servicios Sociales, es mejor acudir a ellos antes que a la familia", siendo este tipo de actitudes más propio de quienes ven más cerca dicha posibilidad y ya ha educado a sus hijos, que entre quienes se encuentran en las primeras fases del ciclo familiar o incluso entre quienes no tienen hijos. En el plano de las representaciones sociales, por tanto, el proceso de privatización de los proyectos de vida familiar se está traduciendo en una redefinición de las normas de solidaridad familiar que, sin abandonar la norma de obligación filial de cuidado, tiende a acentuar también la dimensión de complementariedad, coordinación y supervisión de la ayuda prestada por personas ajenas a la familia así como a acentuar la sociabilidad más que el cuidado personal directo y exclusivo.

La redefinición de la solidaridad entre las generaciones al hilo del desarrollo del Estado de bienestar y de los niveles de bienestar material de ambas generaciones se ha concretado en el plano de los comportamientos en el desarrollo del modelo de relaciones «intimidad a distancia», en virtud del cual la corresidencia de las generaciones se postpone cada vez más en el tiempo de forma que la viudedad y la edad, por sí mismas, han dejado de implicar el reagrupamiento de las generaciones. La familia y singularmente las hijas continúan, no obstante, siendo las principales prestadoras de cuidados y atención a los miembros incapacitados de la red familiar y el papel que ocupan los Servicios Sociales o el mercado es 
Cambios en las relaciones familiares y en la solidaridad...

muy limitado, aunque creciente. En nuestra encuesta, en la que se admitía respuesta múltiple a la pregunta sobre quién cuida de un familiar necesitado de «ayuda o cuidado para la realización de las tareas cotidianas tales como lavarse, vestirse, comer, etc.», también es la familia la principal cuidadora de los miembros necesitados de ayuda, pero también aparece reflejada la tendencia de cambio que afirmamos: en un $15 \%$ de los casos en los que algún ascendiente necesita estos cuidados (padres, abuelos o padres del cónyuge), éstos proceden, en primera respuesta, de no familiares (7\% se encuentra en una residencia y otro $7 \%$ es atendido por servicios sociales o una asistenta), porcentaje que se duplica (32\%) si se consideran también las segundas respuestas. Ciertamente el cuidado por la familia no sólo es la regla, sino también la norma, incluso en una ámbito socioeconómico como el madrileño, fuertemente urbanizado, industrializado y donde el proceso de privatización de los proyectos de vida familiar está ampliamente extendido, pero esta norma está en proceso de redefinición en la dirección hacia una solidaridad más «teledirigida», menos absorbente, más de «emergencia» y que empieza a implicar también en mayor medida a los varones en la prestación de ayudas tradicionalmente consideradas como propias de la mujer.

Ambos procesos de redefinición de la solidaridad familiar, en realidad, no hacen sino apuntar en la misma dirección de reforzamiento de la independencia de los nucleos conyugales dentro de la red familiar similar al que se produjo en las pasadas décadas en el ámbito de la independencia financiera de las generaciones, sin que ello tuviera como consecuencia la erosión de la solidaridad familiar en otras dimensiones. Lo mismo que el desarrollo del sistema de pensiones (y la salarización de la población) han comportado una redefinición de las pautas de relación entre los mayores y sus descendientes en dirección hacia un reforzamiento de la independencia residencial y económica de ambos, así la incorporación de la mujer al mercado de trabajo, la consecuente mejora económica de las familias y el proceso de privatización creciente de los proyectos de vida familiar están llevando también hacia una acentuación del principio de independencia en las relaciones intergeneracionales, sin que ello comporte necesariamente ni una renuncia a la disposición a «ayudar», ni una pérdida del alcance e importancia subjetiva de la sociabilidad familiar para sus miembros. Y en la medida en la que la sociabilidad familiar no pierda su importancia, la red familiar próxima seguirá funcionando como «capital relacional» de reserva en casos de necesidad. 


\section{Aspectos comparativos con otros países}

Es una idea comúnmente extendida que la familia de Europa del sur y, por tanto, la española es mucho más solidaria que la familia del norte de Europa. Varios son los indicadores que en este sentido se pueden citar para fundamentar esta impresión:

- Los jóvenes, como se ha visto, permanecen cada vez más tiempo en el hogar de los padres para poder iniciar su propia biografía familiar sin renunciar a las comodidades y niveles de consumo que han podido lograr en casa de sus padres, aunque éstos se quejen con frecuencia del egoísmo de los hijos y de que los explotan en su beneficio. No obstante, y como hemos visto, esta dimensión de la solidaridad familiar es fundamental para la colocación de los hijos en la estructura social.

- Los mayores necesitados de ayuda son cuidados también casi siempre, como hemos visto, en el ámbito familiar. Tanto el número de hogares unipersonales como la proporción de mayores en residencias de la tercera edad es mucho menor que en los países del centro y norte de Europa. Así, mientras el número de plazas residenciales en España representa sólo el 3\% de la población mayor de 65 años, en Alemania representa un 5,5\%, en Francia un 7,75\% y en Dinamarca un 13,8\%. Por otro lado, mientras en España la proporción de mujeres mayores de 75 años que viven por su cuenta es del $28 \%$, en Francia es el doble (59\%) y en Alemania incluso más (68\%).

- Por lo que se refiere al cuidado de niños, España también se encuentra entre los países de la UE con una relativamente importante proporción de abuelas que cuidan de sus nietos. Así, según el Panel de hogares de la UE de 1994, un $12 \%$ de las mujeres de más de 50 años cuidaban niños frente a un $4 \%$ en Francia o poco más del $5 \%$ en Dinamarca, aunque en Alemania la proporción estaba ligeramente por encima del $10 \%$ mientras que en Italia y Grecia llegaba a alcanzar hasta el 29 y $25 \%$ respectivamente.

Buena parte de esta impresión se ve reforzada también por el mayor tamaño de los hogares y la relativamente baja proporción de familias monoparentales y de hogares unipersonales comparativamente con los países del norte de Europa. Pero la extrapolación de conclusiones sobre la solidaridad familiar a partir de las estadísticas de hogares induce a muchos errores, porque las formas de convivencia se ven muy condicionadas por las condiciones económicas, la coyuntara del mercado de trabajo y el tipo de prestaciones sociales que se reconocen por el Estado de bienestar. 
Cambios en las relaciones familiares y en la solidaridad...

En España, el desarrollo de la protección social ha sido lento y se ha centrado sobre todo en la garantía de ingresos (pensiones y prestaciones por desempleo) más que en la prestación de servicios sociales, que tienen un limitado alcance y se destinan fundamentalmente a los grupos más necesitados. La denuncia del Defensor del Pueblo (1999) de insuficiencia de recursos para el cuidado de los mayores y su demanda a los poderes públicos de una mayor sensibilidad hacia las necesidades de los mayores es ilustrativa en este sentido. Ahora bien, la solidaridad familiar funciona allí donde el mercado y el Estado no llegan, por lo que una parte importante de la solidaridad familiar ha venido inducida por la falta de suficiente protección social por parte del Estado y/o una inadecuada oferta de servicios por el mercado (ausencia de servicios, precios demasiado altos, etc.). En este sentido, las formas de convivencia reflejan tanto el alcance de la solidaridad familiar como también las limitaciones y características específicas de la protección social.

La temprana emancipación de los jóvenes de los hogares de sus padres en los países del norte de Europa, por ejemplo, se ha visto facilitada por la existencia de un mercado de viviendas subvencionadas relativamente extendido así como por la frecuente existencia de becas o préstamos generalizados para el estudio, además de un mercado de viviendas de alquiler mucho mayor y más dinámico que el que existe en los países del sur. Las características específicas de la protección social promueven incluso, puede decirse, la temprana emancipación de los jóvenes del hogar paterno en estos países. Ahora bien esta separación residencial de las generaciones oculta en muchos casos la existencia también de un apoyo económico por parte de los padres. Así, estudios llevados a cabo en Alemania han puesto en evidencia que un $83 \%$ de los jóvenes de 18 a 28 años es económicamente dependiente de sus padres y que las ayudas financieras directas mensuales llegan a alcanzar una media de 375 euros al mes. Por otro lado, y también referido a Alemania, aunque la proporción de hogares unipersonales encabezados por personas mayores es muy superior al que existe en España así como también la proporción de personas en residencias de la tercera edad, 2/3 de los servicios de cuidado y atención a los mayores es realizado por la familia (Nave-Herz, 2002b). Por tanto, las estadísticas de hogares ocultan en gran medida el alcance real y la dinámica de la vida familiar.

De hecho, y al hilo del profundo cambio familiar que están conociendo las sociedades euopeas, en las últimas décadas han surgido distintos estudios nacionales que han tenido por objeto analizar precisamente las características de la sociabilidad familiar y el alcance de la solidaridad 
familiar. Todos los autores de estos estudios coinciden en concluir que a pesar de la creciente reducción del tamaño de los hogares, los individuos, a diferencia de lo que sucedía en el pasado, viven cada vez más inmersos en el marco de una familia compuesta por al menos tres órdenes generacionales, geográficamente no tan separada y con relaciones mutuas frecuentes. Es lo que se ha denominado «familia multigeneracional» (Bertram, 2000; Nave-Herz, 2002) o también «familia multilocal». Por otro lado, y dada la frecuencia de las relaciones intergeneracionales, también se encuenta un intercambio más o menos regular de ayudas dentro de las redes familiares, al menos en el marco de lo que Kellerhals y colaboradores han denominado la «familia restringida» (Attias-Donfut, 1995), esto es, entre los miembros de la familia de origen, y ello a pesar de todos los cambios registrados en las últimas décadas.

Comparar los resultados de estos estudios con los que hemos presentado hasta ahora es, sin embargo, una tarea imposible, pues las metodologías seguidas y, sobre todo, el tipo de indicadores que se han utilizado en los distintos estudios son muy diferentes. No obstante, hay algunos datos que sí pueden compararse y que aunque proporcionan una imagen muy impresionista, sí resultan suficientemente ilustrativos como para poner de relieve que aunque las formas de convivencia estén más individualizadas en los países del centro de Europa, la solidaridad familar juega también en esos países un importante papel en la provisión de bienestar, tanto material, como, sobre todo, inmaterial, que se encuentra lejos de desaparecer con el proceso de individualización.

Así, por lo que se refiere a la frecuencia de contactos, podemos observar en la tabla 21 que la frecuencia de contacto con los padres es también muy intensa en Alemania y Francia, al menos cuando padres e hijos viven en el mismo municipio (lo que no es infrecuente). De hecho no existen diferencias significativas entre los entrevistados de los tres países considerados cuando se controlan los efectos de la distancia, tanto si se consideran los contactos con los padres como si se centra la atención en los contactos de los padres con sus hijos emancipados. No sucede, sin embargo, lo mismo si se considera el conjunto de la muestra, en cuyo caso las familias madrileñas aparecen como más cohesionadas, pero ello tiene su origen probablemente no en la intensidad de los contactos, sino en la mayor dispersión de las redes familiares en las muestras nacionales (como son las de Alemania y Francia). Los contactos con los hermanos, por el contrario, no pueden compararse satisfactoriamente, pues en la encuesta alemana no están aislados de los contactos con los amigos y en la francesa, al considerarse solamente los casos en los que se cita a los hermanos como 
"próximos», los datos están muy distorsionados, pues sólo uno de cada dos entrevistados cita a un hermano/a como "próximo". Esta circunstancia, sin embargo, permite suponer que los contactos con los hermanos pueden estar más extendidos en la familia española que en la francesa, pues tres de cada cuatro entrevistados que tienen un hermano/a en el mismo municipio lo ven al menos una vez al mes. Más en general, los contactos con otros miembros de la red familiar más allá de los padres e hijos pueden ser algo más frecuentes en la familia española, pero cualquier conclusión en este sentido requiere de un estudio comparativo destinado a contrastar precisamente esta hipótesis, pues los datos disponibles no permiten sacar conclusiones empíricamente fundamentadas.

TABLA 18. Frecuencia de contacto personal, telefónico o escrito entre las generaciones (ambos sexos) cuando viven en hogares distintos y en el mismo municipio

\begin{tabular}{|l|c|c|c|c|}
\hline & Francia & Alemania & España - Comunidad de Madrid \\
\hline \multicolumn{4}{|c|}{ Tipo de contacto } & \multicolumn{2}{|c|}{ Personal, tfno, escrito } & \multicolumn{2}{c|}{ Teléfono } & Personal \\
\hline \multicolumn{4}{|c|}{ Contacto del entrevistado con su madre/padres } \\
\hline Una vez por día & 38 & 39 & 38 & 28 \\
\hline Varias veces por semana & - & 32 & 31 & 32 \\
\hline Una vez por semana & 53 & 16 & 14 & 25 \\
\hline Una vez al mes & 8 & 8 & 6 & 13 \\
\hline Una vez al año & 1 & 2 & 2 & 2 \\
\hline Con menor frecuencia & 0 & 2 & 0 & 8 \\
\hline Total & 100 & 100 & 100 & 100 \\
\hline
\end{tabular}

\begin{tabular}{|l|c|c|c|c|}
\hline \multicolumn{5}{|c|}{ Contacto del entrevistado con sus hijos emancipados } \\
\hline Una vez por día & 48 & 38 & 34 & 33 \\
\hline Varias veces por semana & - & 37 & 33 & 34 \\
\hline Una vez por semana & 44 & 11 & 16 & 21 \\
\hline Una vez al mes & 5 & 7 & 8 & 10 \\
\hline Una vez al año & 3 & 4 & 3 & 2 \\
\hline Con menor frecuencia & 0 & 3 & 6 & 0 \\
\hline Total & 100 & 100 & 100 & 100 \\
\hline
\end{tabular}

Notas: La encuesta de Francia corresponde a una muestra nacional de 1952 entrevistados adultos realizada en 1990 y la tabla recoge los porcentajes de contactos de aquellos entrevistados solo que señalan a sus padres como personas «próximas» (un $76 \%$ del total de entrevistados). La encuesta alemana corresponde a una muestra de 423 hogares encabezados por personas de 21 a 34 años a partir de la cual se entrevista también a sus padres y a sus abuelos, lo que supone en total 1.285 entrevistas realizadas en 1990 . De la base de datos original se han aislado los contactos con la madre cuando ambos viven en el mismo municipio. La información no está desagregada en función de tipo de contacto en ninguna de las dos encuestas. En el caso de la encuesta madrileña hemos supuesto que cuando viven a más de una hora de transporte viven en otro municipio.

Fuentes: Para Francia: C. Bonvalet, A. Gotman e Y. Grafmeyer (eds) (1999), La famille et ses proches, INED-PUF, Paris, p. 65. Para Alemania: Deutsches Jugend Institut, Familiensurvey 19881995, Munich, CD con cuestionarios y bases de datos. Para España: G. Meil «Encuesta sobre relaciones familiares en la Comunidad de Madrid». 
TABla 19. Ayudas intercambiadas entre los miembros de la red familiar en distintos países

\begin{tabular}{|c|c|c|c|c|c|}
\hline \multirow{2}{*}{$\begin{array}{c}\text { Ayuda en } 25 \text { años de } \\
\text { matrimonio }\end{array}$} & \multicolumn{2}{|c|}{ Suiza } & \multirow{2}{*}{$\begin{array}{c}\text { Ayudas } \\
\text { "intercambiadas" }\end{array}$} & \multirow{2}{*}{ Bélgica } & \multirow{2}{*}{$\begin{array}{l}\text { España } \\
\text { Madrid }\end{array}$} \\
\hline & Recibidas & Dadas & & & \\
\hline Donaciones & 20 & 22 & Apoyo afectivo & 73 & - \\
\hline Préstamos & - & 13 & Apoyo financiero & 15 & 18 \\
\hline Ayuda doméstica & 20 & 61 & Ayuda doméstica & 30 & 26 \\
\hline Hospedaje & 10 & 42 & Cuidados & 7 & 11 \\
\hline Cuidado de niños & 25 & 33 & Cuidado de niños & 46 & 51 \\
\hline
\end{tabular}

Notas: La encuesta de Suiza se basa en una muestra de 817 familias entrevistadas entre 50 y 57 años y se refiere a ayudas dadas o recibidas a lo largo de los 25 años que como media llevan casados. La encuesta belga se basa en una muestra de 569 individuos de todas las edades y se refiere a "intercambios", sin especificar si dan o reciben ni el período temporal al que se refieren, por ello, y a efectos comparativos, se han tomado para Madrid los porcentajes más altos de ayudas dadas o recibidas. En los tres casos los porcentajes representan ayudas a cualquier miembro de la red de parentesco y la diferencia hasta cien de cada valor representa el porcentaje de familias entrevistadas que no han recibido o dado el tipo de ayuda considerado (así, por ejemplo, el $20 \%$ de familias suizas han recibido alguna donación de algún familiar durante su vida conyugal).

Fuentes: Bawin-Legros et al., «Les limites de l'entraide intergenerationelle» y Kellerhals, J. et al., "Les formes du réseau de soutien dans la parenté» en Attias-Donfut, Cl. (1995), Les solidarités entre générations, Nathan, Paris

Todos estos estudios evidencian también que la sociabilidad familiar sienta las bases para el intercambio de ayudas cuando éstas son requeridas y hay capacidad para prestarlas, sobre todo, en las relaciones intergeneracionales. Ahora bien, los estudios manejados sobre Bélgica, Francia, Suiza y Alemania evidencian en todos los casos una fuerte verticalidad, consanguinidad y polarización. Verticalidad en el sentido de que se da una fuerte concentración de la sociabilidad familiar y sobre todo de las ayudas en las relaciones intergeneracionales. Consanguinidad en el sentido de una mayor intensidad, o de la percepción de la misma, en lo que hemos denominado "familia propia", esto es, se ve más a los familiares consanguíneos que a los políticos. Y polarización en el sentido tanto del papel central desempeñado por las mujeres como por el mayor flujo de ayuda de los padres hacia los hijos, aunque las percepciones subjetivas sobre los intercambios a lo largo del tiempo tienden a reflejar un sentimiento de equilibrio entre el dar y el recibir, pues además de ayudas específicas también se «intercambia» compañía, afecto y apoyo emocional. La "familia restringida" sigue jugando así en todos estos países un importante papel tanto en el plano subjetivo como en el plano objetivo de las ayudas concretas a lo largo del ciclo familiar. A pesar del profundo cambio familiar registrado y a pesar de la existencia de indicadores de individualización más evidentes (hogares unipersonales, divor- 
cio, familias monoparentales), la familia no ha dejado de ser «una comunidad solidaria" también en estos países, aunque, como se apunta también en España, esta solidaridad sea cada vez más una solidaridad de carácter complementario y de «emergencia».

\section{Referencias bibliográficas}

Alberdi, I.; FlaqueR, L. e Iglesias de Ussel, J. (1994): Parejas y Matrimonios. Actitudes, comportamientos y experiencias, Madrid, Ministerio de Asuntos Sociales.

ATtTIAS-DONFUT, C. (ed) (1995), Les solidarités entre générations. Vieillesse, Familles, État, Nathan, Paris.

BECK, U. (1997): La sociedad del riesgo, Barcelona, Paidós.

BERTRAM, H. (2002), «Die verborgenen familiären Beziehungen in Deutschland: Die multilokale Mehrgenerationenfamilie" en KOHLI, M. y SzYDLIK, M. (eds), Generationen in Familie und Gesellschaft, Opladen, Leske+Budrich.

BIEN, W. (ED)(1994), Eigeninteresse oder solidarität, Opladen, Leske + Budrich.

Del CAMpo, S. y NAVARRo, M. (1985), Análisis sociológico de la familia española, Barcelona, Ariel.

DE PABLO, A. (1976) «La familia española en cambio» en Fundación FOESSA, Estudios sociológicos sobre la situación social de España 1.975, Madrid, Euroamérica.

Eurostat (2002), La situation sociales dans l'UE, Luxemburgo, Oficiana de estadísticas de la Unión Europea.

FUNDACIÓN ENCUENTRO, CECS (2001), «La dependencia entre los mayores» en Informe España 2001, Madrid, distribuido por Siglo XXI.

GARRIDO, L. Y REQUENA, M. (1996): La emancipación de los jóvenes en España, Instituto de la Juventud, Madrid.

INE (1993), Encuesta Sociodemográfica, Tomo II, Resultados Nacionales, Vo.1 Hogares y Familias, Madrid.

INE (2004), Cambios en la composición de los hogares, censos 2001, Madrid.

MEIL, G. (1999), La postmodernización de la familia española, Madrid, editorial Acento. MEIL, G. (2000), Imágenes de la solidaridad familiar, CIS, Madrid.

NAVE-HERZ, R.M. (2002), «Die Mehrgenerationen-Familie -eine soziologische Analyse-» en WALPER, S. y PEKRUn, R. (eds), Familie und Entwicklung, Göttingen, Hogrefe Verlag.

NAVE-HERZ, R. (2002b) (ed), Family Change and Intergenerational Relations in Different Cultures, Ergon, Würzburg.

REHER, D.S. (1.996), La familia en España, Pasado y presente, Madrid, Alianza editorial. SPITZE, G. y LoGAN, J. (1996), Family Ties, Philadelphia, Temple University Press.

SzYDLIK, M. (2000), Lebenslange Solidarität?, Opladen, Leske+Budrich.

\section{Notas}

1 El trabajo de campo ha sido realizado por la empresa Invymark. El procedimiento de muestreo aplicado ha sido estratificado por municipios y proporcional al número de hogares, con afijacón proporcional por cuotas. 
${ }^{2}$ Se introduce el calificativo de "propios» y no el habitualmente utilizado de «consanguíneos», porque se quiere incluir en dicha categoría tanto al cónyuge como a los eventuales cónyuges de la fratría, que no entran dentro de la definición de "consanguíneos».

${ }^{3}$ Estos resultados se evidencian muy consistentes y se ven confirmados tanto si se realiza un análisis de regresión lineal de la frecuencia de contactos para cada uno de los hermanos aisladamente, como si se considera al hermano/a que se ve con mayor frecuencia o el porcentaje de hermanos que se ve semanal o mensualmente, controlados los efectos de la distancia y el sexo.

4 En una escala de 1 a 10 en la que se pedía valoraran su relación con su padre y con su madre, las mujeres que vivían en pareja valoraban esta relación,como media, en 8,7 y 8 puntos respectivamente frente a 9 y 8,7 de las casadas. Los valores correspondientes para los varones encuestados se elevaban a 8,5 y 7,9 entre quienes convivían y 8,5 y 8,1 entre los casados. Todo un indicador de cómo se han privatizado los proyectos de vida familiar.

5 CIS, estudio 2244. 